\title{
THE EFFECT OF L-THYMIDINE, ACYCLIC THYMINE AND 8-BROMOGUANINE ON THE STABILITY OF MODEL G-QUADRUPLEX STRUCTURES
}

\author{
Anna Aviñó ${ }^{a, b, *}$, Stefania Mazzini ${ }^{\text {c, Carme Fàbrega }}{ }^{\text {a,b }}$, Pablo Peñalver ${ }^{\text {d,e }}$, Raimundo \\ Gargallo $^{\mathrm{f}}$, Juan Carlos Morales ${ }^{\mathrm{d}, \mathrm{e}}$, Ramon Eritja ${ }^{\mathrm{a}, \mathrm{b}, *}$ \\ a Institute for Advanced Chemistry of Catalonia (IQAC), CSIC, Jordi Girona 18-26, 08034 \\ Barcelona. Spain \\ b Networking Center on Bioengineering, Biomaterials and Nanomedicine (CIBER-BBN), Jordi \\ Girona 18-26, 08034 Barcelona. Spain

\begin{abstract}
c Department of Food, Environmental and Nutritional Sciences (DEFENS), Section of Chemical and Biomolecular Sciences, University of Milan, Via Celoria 2, 20133 Milan, Italy

d Department of Biochemistry and Molecular Pharmacology, Instituto de Parasitología y Biomedicina, CSIC, Parque Tecnológico Ciencias de la Salud, Avda. del Conocimiento, s/n, 18016 Armilla, Granada, Spain

e Department of Bioorganic Chemistry, Instituto de Investigaciones Químicas, CSIC - Universidad de Sevilla, Américo Vespucio 49, 41092, Sevilla, Spain

f Department of Chemical Engineering and Analytical Chemistry, University of Barcelona, Diagonal 64708028 Barcelona, Spain
\end{abstract}

*Corresponding Authors. Tel. +34 934006100; fax: +34 932045904. Email addresses: aaagma@cid.csic.es (A. Aviñó), recgma@cid.csic.es (R. Eritja)

\begin{abstract}
Background: Guanine-rich oligonucleotides are capable of forming tetrahelical structures known as G-quadruplexes with interesting biological properties. We have investigated the effects of site-specific substitution in the loops and in the tetrads model G-quadruplexes using thymine glycol nucleic acid (GNA) units, L-thymidine and 8-Br-2'-deoxyguanosine.

Methods: Modified oligonucleotides were chemically synthesized and spectroscopic techniques were used to determine the relative stability of the modified G-quadruplex. The double 8-BrdUmodified quadruplexes were further characterized by Nuclear Magnetic Resonance. Binding to thrombin of selected quadruplex was analyzed by gel electrophoresis retention assay.

Results: The most interesting results were found with a 8-bromoG substitution that had the larger stabilization of the quadruplex. NMR studies indicate a tight relationship between the loops and the tetrads to accommodate 8-bromoG modifications within the TBA.

Conclusions: The substitutions of loop positions with GNA T affect the TBA stability except for single modification in T7 position. Single L-thymidine substitutions produced destabilization of TBA. Larger changes on quadruplex stability are observed with the use of 8-bromoG finding a
\end{abstract}


single substitution with the highest thermal stabilization found in thrombin binding aptamers modified at the guanine residues and having good affinity for thrombin. Double 8-BrdG modification in anti positions of different tetrads produce a conformational flip from syn to anti conformation of $8-\mathrm{Br}-\mathrm{dG}$ to favor loop-tetrad interaction and preserve the overall TBA stability. General Significance: Modified guanine-rich oligonucleotides are valuable tools for the search for G-quadruplex structures with higher thermal stability and may provide compounds with interesting protein-nucleic acid binding properties.

\section{Keywords}

Thrombin Binding Aptamer, Thymine Glycol Nucleic Acid, L-Thymidine, 8-Bromo-2'deoxyguanine, G-quadruplex, NMR

\section{Introduction}

Oligonucleotides are currently used in several areas such as diagnostics, therapeutics or in nanotechnology. Most of these applications rely on the fact that nucleic acids are versatile molecules that can adopt several specific structures. Among them, G-quadruplex has been highlighted in recent years. This structure is formed in G-rich sequences by the association of several units of G-tetrads that are stabilized by cations [1]. This structure is particularly interesting as it has been found in relevant regions such as in the promoter or telomeric regions, as well as in oncogenes [2]. It is possible to modulate the diverse biological functions of nucleic acids by the incorporation of site-specific chemical modifications. In this regard, thrombin binding aptamer (TBA) has attracted considerable attention and several modifications have been described to improve their thermal stability, nuclease resistance and affinity for the target thrombin [3, 4]. TBA is a 15-base sequence, d(GGTTGGTGTGGTTGG) with anticoagulant properties. It folds into antiparallel G-quadruplex structure consisting in two G-tetrads connected by two TT loops and a central TGT loop (Fig. 1a). Particularly, the two TT loops interact with the thrombin anion exosite I. The central loop TGT is in close proximity to the heparin binding site of a different thrombin molecule resulting in TBA interacting with two thrombin molecules but only inactivating one of them [5, 7-8]

Engineering TBA can provide a significant amount of relevant information for biomedical and structural studies. The structural factors controlling the structure of TBA are not only restricted to the G-tetrads; loops play an important role in the folding structure and in the binding to the target. We recently demonstrated that a higher-order structure of TBA can be stabilized by simple specific loop modifications [9]. Nucleotides with special structural or physicochemical properties have been specifically substituted by natural nucleotides of TBA [3]. For example, locked nucleic acids (LNA) [10,11], unlocked nucleic acids (UNA) [12] or 2'-deoxy-2'-fluoro$\beta$-D-arabinonucleic acid (2'F-ANA) [13] are derivatives with interesting backbone features that 
have been introduced in different positions of TBA. In addition, modification of nucleobases containing alkylating moieties or bases with different electronic density has been studied in order to understand the folding topology and stability of TBA [14].

TBA is attracting considerable attention since it shows remarkable in vitro anticoagulant properties and some mutants based on their structure are in advanced clinical trials [15]. Moreover, some G-quadruplex structures, including TBA, have shown antiproliferative activity in cancer cells [16]. Although there is no clear relationship between the structure and the biophysical properties in the antiproliferative behavior [16] recent research has taken this direction [17-19].

The studies based on the folding topology of TBA may be also exploited in diagnostics or in biosensing applications. Recently, TBA was used as a DNA aptasensor for metal determination [20].

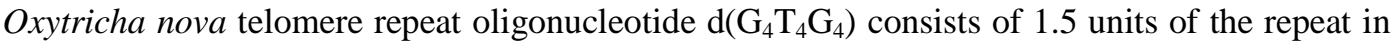
telomers of Oxytricha nova. It is a symmetric dimeric G-quadruplex structure with four Gtetrads and T4 loops which span the diagonal of the end G-tetrads (Fig. 1a) [21].

In this study, we prepared a group of TBA variants with several types of modifications including glycol nucleic acid thymine (GNA T) and L-thymidine (Fig. 1b), which were introduced in different loop residues. These two different types of nucleic acids backbones were studied in the loop positions of TBA. First, we studied the effect of substituting TBA's thymidines for GNA T units. This thymine derivative is a propylene glycol nucleotide building block with three carbon atoms linked by phosphodiester bonds [22]. GNAs form antiparallel duplex structures according to the Watson-Crick rules [22]. These derivatives have never been tested in the loops of quadruplex.

Secondly, we have modified single positions in the loop regions of TBA with L-thymidine in an effort to understand the effect of nucleotide chirality in specific loop residues. Oligonucleotides containing L-nucleotides are interesting derivatives due to their good nuclease resistance properties and have found different applications in aptamers or in the nanotechnological field. L-thymidine has been introduced in a tetramolecular G-quadruplex $\left[\mathrm{TG}_{4} \mathrm{~T}\right]_{4}[23]$ or in a monomolecular G-quadruplex such as anti-HIV aptamer [24] or TBA [25]. In addition, TBA has been modified with enantiomeric nucleosides in different positions. Stability and bioactivity of TBAs modified with D-/L-isothymidine showed a position-dependent effect [26].

Then, we prepared several TBA variants with modified tetrads. We selected 8-Br-dG (Fig. 1b) that is a nucleotide that stabilizes a syn conformation of the glycosidic bond by steric hindrance between the $\mathrm{Br}$ and the ribose moiety. This modification has been shown to stabilize quadruplex structures when is substituting guanines that are in syn position [27-29]. Specifically, it has been demonstrated that $8-\mathrm{Br}-\mathrm{dG}$ in appropriate positions increases the affinity of TBA due to the stabilizing enhancement of the G-quadruplex structure. Nevertheless, the effect of this 
derivative in anti positions or the additions of more than one modification was not yet studied. In addition, 8-Br-2'-deoxyguanosine was used to replace $\mathrm{G}$ in specific positions of G-tetrads of the Oxytricha nova telomere repeat oligonucleotide (Fig. 1).

Here we report the effect of the substitution of natural nucleosides by modified nucleotides with special structural features either in the loops or in the G-tetrads of model G-quadruplexes focusing on the folding topology and structural stability of the resulting variants.

a)

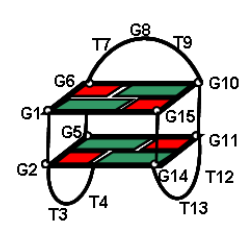

b)
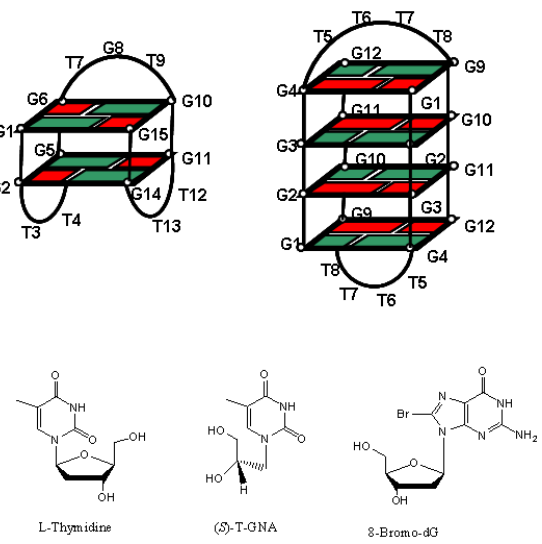

Fig.1. (a) Scheme of the TBA and Oxytricha nova telomere repeat oligonucleotide, in red dG in syn conformation and in green dG in anti. (b) Chemical structure of L-thymidine and (S)-TGNA, 8-Br-2'-deoxyguanosine residues used for the synthesis of modified G-quadruplex.

\section{Materials and methods}

\subsection{Oligonucleotide synthesis}

The oligonucleotides listed in Table 1 were synthesized on a DNA/RNA Applied Biosystems 394 synthesizer by solid-phase 2-cyanoethylphosphoroamidite chemistry at $1 \mu$ mol scale. Sequences containing $8-\mathrm{BrdG}$ were prepared using the commercially available 5'-O-(4,4'dimethoxytrityl)-8-Br-2'-deoxyguanosine-3'-O-(2-cyanoethyl-N,N-diisopropyl)phosphoramidite (Link Technologies).

The 2'-Deoxy-L-thymidine (Carbosynth) was protected with the dimethoxytrityl (DMT) group and further converted to the corresponding $\beta$-cyanoethylphosphoramidite according to standard procedures [24].

The GNA Thymine monomer (2-(S)-1-(4,4'-dimethoxytrytiloxy)-4-(thyminyl)butyl (2cyanoethyl) ( $N$ - $N$-diisopropyl) phosphoramidite ) was obtained from $(R)-(+)$-glycidol as described [22].

The oligonucleotides were synthesized in the DMT-ON mode. After the standard ammonia treatment (conc. $a q . \mathrm{NH}_{3}, 55^{\circ} \mathrm{C}$, overnight), the oligonucleotides were purified using Glen- 
Pack $^{\mathrm{TM}}$ DNA purification cartridges (Glen Research) except for those containing GNA-T. In this case, the solid support was previously treated 0.1 M DBU/ACN for five minutes and then washed with $1 \% \mathrm{Et}_{3} \mathrm{~N} / \mathrm{CAN}$ and finally treated with concentrated ammonia.

All the oligonucleotides were analyzed by HPLC. Semipreparative column: X-bridge ${ }^{\mathrm{TM}}$ OST $\mathrm{C}_{18}(10 \times 50 \mathrm{~mm}, 2.5 \mu \mathrm{m}) ; 10$ min linear gradient from $0 \%$ to $30 \%$, flow rate $2 \mathrm{~mL} / \mathrm{min}$; solution A was $5 \% \mathrm{ACN}$ in $0.1 \mathrm{M}$ aqueous TEAA and $\mathrm{B} 70 \% \mathrm{ACN}$ in $0.1 \mathrm{M}$ aqueous TEAA and confirmed by Matrix-assisted laser desorption ionization time-of-flight (MALDI-TOF) spectra (Table 1).

\section{$2.2 U V$ and $C D$ spectroscopy of TBA variants}

Oligonucleotides were resuspended in $10 \mathrm{mM}$ cacodilate buffer and $100 \mathrm{mM} \mathrm{KCl} \mathrm{pH} 7.0$ to form solutions with a concentration between $2-6 \mu \mathrm{M}$. These solutions were heated at $85^{\circ} \mathrm{C}$ and slowly cooled down to room temperature for annealing. The resulting solutions were stored at $4^{\circ} \mathrm{C}$ for one night. The thermal (denaturing and annealing) curves were obtained following the change of the absorption at $295 \mathrm{~nm}$ from $20^{\circ} \mathrm{C}$ to $80^{\circ} \mathrm{C}$ with a linear temperature ramp of 0.5 ${ }^{\circ} \mathrm{C} / \mathrm{min}$ on a JASCO V-650 spectrophotometer equipped with a Peltier temperature control. Melting temperatures $\left(T_{m}\right)$ were determined as described elsewhere [30] using home-made routines written in Matlab code (Table 1).

Thermal difference spectra (TDS) were obtained by subtraction of the spectra obtained at $20^{\circ} \mathrm{C}$ from spectra obtained at $80^{\circ} \mathrm{C}$ using the same buffer [31]. The scan speed was $100 \mathrm{~nm} / \mathrm{min}$ with data collection of 1 point $/ \mathrm{nm}$. Results are shown in the supplementary content.

The CD spectra were recorded on a JASCO spectropolarimeter J-815. Spectra were registered at $15^{\circ} \mathrm{C}$ over a range of $220-320 \mathrm{~nm}$ with a scanning speed of $100 \mathrm{~nm} / \mathrm{min}$, a response time of $4 \mathrm{~s}$, $0.5 \mathrm{~nm}$ data pitch and $1 \mathrm{~nm}$ bandwidth. The samples were dissolved in the above buffer annealed, then slowly cooled down to room temperature and left at $4^{\circ} \mathrm{C}$ at least one night.

Table 1. Sequence, melting temperature $\left(T_{m}\right)$ and mass spectra of $T B A$ and $\mathrm{G}_{4} \mathrm{~T}_{4} \mathrm{G}_{4}$ derivatives used in this study. $\mathrm{T}^{\mathrm{L}}:$ L-thymidine, $\mathrm{T}^{\mathrm{N}}:(S)$-GNA-T, $\mathrm{G}^{\mathrm{Br}}: 8-\mathrm{Br}-2$ '-deoxyguanosine.

\begin{tabular}{|l|l|l|l|l|l|}
\hline Name & Sequence & $T_{m}{ }^{\mathrm{a}}\left({ }^{\circ} \mathrm{C}\right)$ & $\Delta T_{m}$ & $\mathrm{M}_{\text {calc }}$ & $\mathrm{M}_{\text {found }}$ \\
\hline TBA & GGTTGGTGTGGTTGG & 49.6 & - & 4726.0 & 4726.6 \\
\hline TBA4GNAT & GGTT $^{\mathrm{N}}$ GGTGTGGTTGG & 36.9 & -12.7 & 4684.4 & 4682.8 \\
\hline TBA7GNAT & GGTTGGT $^{\mathrm{N}}$ GTGGTTGG & 54.8 & +5.2 & 4684.4 & 4686.4 \\
\hline TBA9GNAT & GGTTGGTGT $^{\mathrm{N}}$ GGTTGG & 40.1 & -9.5 & 4684.4 & 4683.8 \\
\hline TBA7,9GNAT & GGTTGGT $^{\mathrm{N}} \mathrm{GT}^{\mathrm{N}}$ GGTTGG $^{\mathrm{N}}$ & 38.6 & -11 & 4642.2 & 4643.7 \\
\hline TBA3,12GNAT & GGT $^{\mathrm{N}}$ TGGTGTGGT $^{\mathrm{N}}$ TGG & 47.1 & -2.5 & 4642.2 & 4644.7 \\
\hline
\end{tabular}




\begin{tabular}{|c|c|c|c|c|c|}
\hline TBA4,13GNAT & GGTT $^{\mathrm{N}}$ GGTGTGGTT $^{\mathrm{N}}$ GG & 37.5 & -12.1 & 4642.2 & 4644.6 \\
\hline TBA7LT & GGTTGGT $^{L}$ GTGGTTGG & 48.9 & -0.7 & 4726.0 & 4726.1 \\
\hline TBA4LT & GGTT $^{L}$ GGTGTGGTTGG & 46.7 & -2.9 & 4726.0 & 4729.3 \\
\hline TBA3LT & GGT $^{\mathrm{L}} \mathrm{T}^{\mathrm{L}}$ GGTGTGGTTGG & 45.5 & -4.1 & 4726.0 & 4729.3 \\
\hline TBA2BrG & GG $^{\mathrm{Br}}$ TTGGTGTGGTTGG & 47.1 & -2.5 & 4804.9 & 4802.5 \\
\hline TBA5BrG & GGTTG $^{\text {Br }}$ GTGTGGTTGG & 56.9 & +7.3 & 4804.9 & 4803.6 \\
\hline TBA2,11BrG & GG $^{\mathrm{Br}}$ TTGGGTGTGG ${ }^{\mathrm{Br}}$ TTGG & 53.2 & +3.6 & 4883.8 & 4480.8 \\
\hline TBA2,6BrG & GG $^{\mathrm{Br}}$ TTGG $^{\mathrm{Br}}{ }^{\text {TGTGGTTGG }}$ & 40.8 & -8.8 & 4883.8 & 4885.1 \\
\hline $\mathrm{G}_{4} \mathrm{~T}_{4} \mathrm{G}_{4}$ & GGGGTTTTGGGG & 59 & - & 3786.4 & 3785.2 \\
\hline $\mathrm{G}_{4} \mathrm{~T}_{4} \mathrm{G}_{4} 2 \mathrm{BrG}$ & GG $^{\mathrm{Br}}$ GGTTTTGGGG & - & - & 3865.3 & 3864.4 \\
\hline $\mathrm{G}_{4} \mathrm{~T}_{4} \mathrm{G}_{4} 3 \mathrm{BrG}$ & GGG $^{\mathrm{Br}}$ GTTTTGGGG & 71.3 & +12.3 & 3865.3 & 3864.4 \\
\hline
\end{tabular}

${ }^{\mathrm{a}} 10 \mathrm{mM}$ sodium cacodilate, $100 \mathrm{mM} \mathrm{KCl} \mathrm{pH} 7$. Uncertainty $0.5^{\circ} \mathrm{C}$

\subsection{NMR spectroscopy of TBA variants}

The oligonucleotides were dissolved in $\mathrm{H}_{2} \mathrm{O} / \mathrm{D}_{2} \mathrm{O}(90: 10 \mathrm{v} / \mathrm{v})$ at a $0.2 \mathrm{mM}$ concentration, in presence of $5 \mathrm{mM} \mathrm{KCl}, 10 \mathrm{mM} \mathrm{K} \mathrm{HPO}_{4} / \mathrm{KH}_{2} \mathrm{PO}_{4}$ phosphate buffer, $\mathrm{pH}$ 6.9. Samples were heated at $85^{\circ} \mathrm{C}$ for 1 minute and then cooled down to room temperature and left at $4^{\circ} \mathrm{C}$ overnight.

The NMR spectra were recorded on a Bruker Avance 600 spectrometer operating at a frequency of $600.10 \mathrm{MHz}$ for ${ }^{1} \mathrm{H}$ with a TXI probe (inverse triple-resonance). The spectra were recorded at variable temperature ranging from $5{ }^{\circ} \mathrm{C}$ to $55^{\circ} \mathrm{C}$ with TOPSPIN (v.1.3). Chemical shifts $(\delta$ ) were measured in ppm and referenced to external DSS (2,2-dimethyl-2-silapentane-5-sulfonate sodium salt) set at $0.00 \mathrm{ppm}$.

Phase sensitive NOESY spectra were acquired at $25^{\circ} \mathrm{C}$ and $5^{\circ} \mathrm{C}$ in TPPI mode, with $2 \mathrm{~K} \mathrm{x} 512$ complex FIDs. Mixing times of 100 and 300 ms. TOCSY spectra were acquired with the use of a MLEV-17 [32] spin-lock pulse (field strength $10.000 \mathrm{~Hz}, 60 \mathrm{~ms}$ total duration). The program Sparky (UCSF) [33] was used to assign the NOESY cross-peaks following the well-established strategy.

\subsection{Thrombin-binding assay}

The TBAs variants $(0.3 \mu \mathrm{M})$ were mixed with increasing concentrations of thrombin. The mixtures were left to react for $1 \mathrm{hr}$ at room temperature. Complexes formation were analyzed on a $10 \%$ polyacrylamide gel at $80 \mathrm{~V}$, at $4^{\circ} \mathrm{C}$ for $4 \mathrm{~h}$ in $100 \mathrm{mM}$ Tris $\mathrm{pH} 7.4,50 \mathrm{mM} \mathrm{AcOH}, 5 \mathrm{mM}$ EDTA, $12.5 \mathrm{mM} \mathrm{Mg}(\mathrm{OAc})_{2}$. Images were taken using Fujifilm las1000 Intelligent Dark Box using SyBR-Green staining and analyze with ImageJ 


\section{Results and discussion}

\subsection{Rigid versus flexible nucleoside analogues in the loop regions}

Extensive work has been done introducing conformationally restricted nucleosides into TBA. For example, we introduced guanine pseudosugars containing bicyclo[3.1.0]hexane instead of the ribose unit with restricted sugar puckering (North or South) and glycosidic angle (anti or syn) [35]. The results showed that when $\mathrm{dG}$ 's in syn positions were substituted by syn methanocarba-dG nucleotides, the resulting TBA variants have similar stability than native TBA. However, the modification was differently tolerated in the two G-tetrads of the TBA. In addition, the glycosyl conformation is more restrictive for TBA stability than the sugar puckering [35]. Similarly, 2'F-ANA residues that favor anti conformation were introduced in the TBA. In this case, when the syn dGs of the tetrads were substituted, the resulted variant showed alternative G-quadruplex conformation [13]. LNA derivatives, which are characterized by a restricted $\mathrm{C} 3$ '-endo sugar pucker and syn conformation were also introduced in several positions of TBA. The results confirmed that LNA substitution in defined positions produced, syn-anti switch of glycosidic angle and, therefore, a mixture of alternative G-quadruplex structures were produced $[10,11]$.

Flexible nucleic acids derivatives have been also introduced in the TBA. Unlocked Nucleic Acids (UNA) derivatives have been introduced in TBA loop positions inducing a site-dependent stabilization of TBA [12]. For this reason, here we have studied the effect of the unlocked GNA $\mathrm{T}$ modification in the loop regions of TBA. This compound contains a flexible and short linker between the nucleobase and phosphate that leads to a decrease in duplex stability respect to a natural thymidine when incorporated into DNA and to an increase in Tm's on all GNA duplexes with respect to DNA duplexes [22]. Specifically we have prepared TBA variants having thymidines 4, 7 and 9 replaced by GNA-T and double-modified TBA variants having modified thymidines in the upper TGT loop (positions 7 and 9), and thymidines in the TT lower loops (positions 3 and 12 and positions 4 and 13).

In order to analyze the effect of these chemical modifications in the stability of the TBA structure we have recorded the corresponding melting curves. Unmodified TBA has a $T_{m}$ of 49.5 ${ }^{\circ} \mathrm{C}$ and shows a CD spectrum with positive peaks at 295 and $245 \mathrm{~nm}$ as well as a negative peak at $265 \mathrm{~nm}$ (Fig 2). These features agree with those reported previously for antiparallel Gquadruplex [1,7].The thermal difference spectra (TDS) of TBA also exhibited a signature characteristic of an antiparallel G-quadruplex structure with two negative peaks $(265 \mathrm{~nm}, 295$ $\mathrm{nm})$ and two positive peaks (245nm, $275 \mathrm{~nm})$ [31] (Fig S1). 


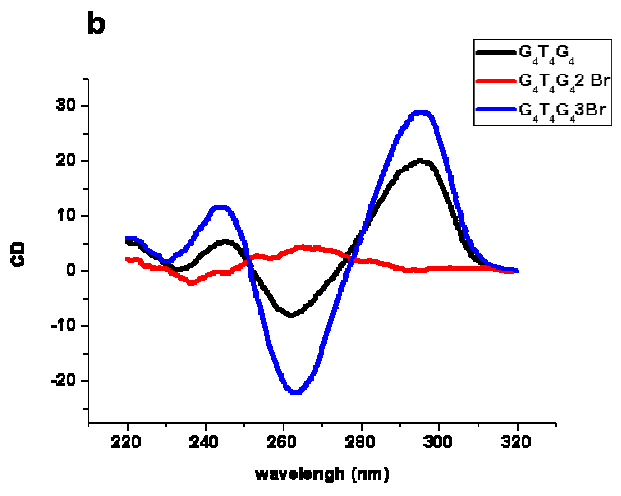

c
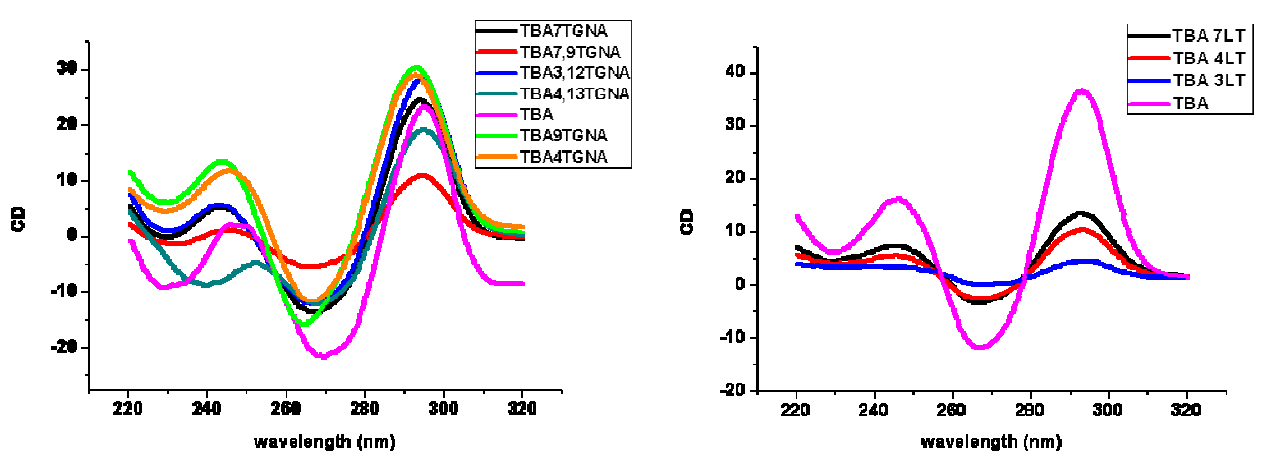

Fig. 2. CD spectra of TBA variant containing a) 8-BrdG, b) GNAT and c) LT in 10mM Sodium cacodilate $100 \mathrm{mM} \mathrm{KCl} \mathrm{pH7.}$

GNA T substitution in position 7 of the central TGT loop produced a thermal stabilizing effect with $\Delta \mathrm{Tm} 5.2^{\circ} \mathrm{C}$ (Table 1). This position is very permissive to be modified [3]. However, thymidine located in position 9 although is present in the same TGT upper loop is very sensitive to the modification as the substitution of $\mathrm{T}$ by GNAT at this position decreases the thermal stability in $9.5^{\circ} \mathrm{C}$. Similarly, when $\mathrm{T} 7$ and T9 were substituted by GNAT the resulted variant was very unstable presenting a $T_{m}$ of $38.6^{\circ} \mathrm{C}$. The lower TT loops of TBA were also very sensitive to modifications, especially changes in positions 4 and 13 that in the unmodified TBA forms a hydrogen bond [8]. In this case, TBA4GNAT is very unstable having a $T_{m}$ of $36.9{ }^{\circ} \mathrm{C}$. Similar results were obtained with TBA4,13GNAT that showed a very low thermal transition $\left(T_{m} 37.5^{\circ} \mathrm{C}\right)$, whereas TBA3,12GNAT is more stable $\left(T_{m} 47.1^{\circ} \mathrm{C}\right)$ indicating that the GNAT modification is more adapted in the overall TBA structure in positions 3 and 12. According to CD spectra, all the TBA GNAT variants showed antiparallel quadruplex structures. TBA7,9 GNAT was the most featureless, implying a less structured oligonucleotide (Fig. 2). TBA variants with GNAT modifications showed similar TDS than TBA. Based on these data we can conclude that, although GNAT contains a short backbone, it has a similar behavior as UNA derivatives [12,34]. Both derivatives increase TBA stability in position 7 [12]. In addition, 
multiple UNA modifications in TBA were also studied [34]. Similar to our work with GNAT, a position-dependent effect was observed being position 7, 3 and 12 the most tolerant in the TBA stability.

\subsection{Presence of L-thymidine in the loop regions}

Next, we studied the introduction L-thymidine, the enantiomer of natural $\mathrm{T}$, in single loop positions of TBA. According to thermal transition, the substitution of $\mathrm{T}$ by $\mathrm{T}^{\mathrm{L}}$ produced a destabilization of the TBA. Position 7 was again the most permissive position with a $T_{m}$ similar to that of TBA but modification in position 3 or 4 produced TBA variants less stable than TBA with a $\Delta T_{m}$ of -4.1 and $-2.9^{\circ} \mathrm{C}$ respectively. The CD spectrum of TBA3LT is almost flat but the rest of the modified TBA variants still maintained the CD antiparallel profile. TDS of TBA7LT is similar to TBA and TBA3LT is the most featureless. The modification with multiple Lderivatives in the tetrads and in the loops of TBA has been studied in the bibliography [25]. Heterochiral TBA analogues resulted in less stable structures than TBA. However, in the case that the central loop and tetrads are modified the resulted variant is more stable indicating their close relation. Tuning with L-nucleotides is a good strategy to improve nuclease activity without compromising thermal stability in certain positions of the G-quadruplex. However, from our work it is envisaged that small number of modifications seems to be detrimental for TBA quadruplex stability.

\subsection{Unexpected stabilization effects from 8-bromo-guanine modifications}

It has been described that modified TBA's carrying 8-BrdG substitutions for guanines that are in syn conformation improve the affinity for thrombin as well as the stability of the resulting TBA variant [27]. This is in agreement with the preference of 8-bromo-G to be in syn conformation. Additionally, this nucleoside was also used as a single chemical probe in a telomeric sequence [29].

We have prepared modified TBA carrying one 8-BrdG substituting a guanine in syn conformation in the native TBA (position 5) and a guanine in anti (position 2). As well as several double-modified TBA's. In the case of a single 8-BrdG substitution for a $\mathrm{G}$ in anticonformation (position 2, TBA2BrG), the melting temperature decreases as expected but only by $2.5^{\circ} \mathrm{C}$. In contrast, in single $8-\mathrm{BrdG}$ substitution for a $\mathrm{G}$ in anti-conformation (position 5 , TBA5BrG), induce a high increase of the $T_{m}\left(\Delta T_{m} 7.3^{\circ} \mathrm{C}\right)$. These results are expected as the addition of a derivative with preference for the syn conformation in a position that is occupied for a $\mathrm{G}$ residue in anti conformation produces a small penalty in term of thermal stability but the derivative is well adapted in an antiparallel-G-quadruplex structure. However, the introduction of 8-BrdG that prefer syn conformation in a syn position produces a modified TBA with much 
more stability. In both cases, the CD spectra reveal an antiparallel G-quadruplex profile similar to that of the native TBA.

The double modification of TBA by $8-B r d G$ produced unexpected results. When we introduce in two 8-Br-dG modifications in position where guanines are in anti conformation in different G-tetrads of TBA the resulting variant (TBA2,6BrG) is less stable than TBA with a $T_{m}$ of 40.8 ${ }^{\circ} \mathrm{C}$. CD and TDS features also confirm the formation of a destabilized antiparallel TBA structure (Fig. 2 and S1). However, when the two guanines that are in anti conformation are replaced by 8-BrdG (that prefer syn conformation) in the same tetrad, the resulting variant (TBA2,11BrG) showed an unexpected increase of thermal stability compared with TBA $\left(T_{m} 53.8^{\circ} \mathrm{C}, \Delta T_{m}\right.$ $+3.6^{\circ} \mathrm{C}$ ). Interestingly, the $\mathrm{CD}$ spectrum was similar to the $\mathrm{CD}$ spectrum of native TBA but the $245 \mathrm{~nm}$ positive band is slightly shifted, denoting small modifications in the structure. The TDS feature of TBA variants containing 8-BrdG are similar to that of TBA, except for TBA2,6BrG which even though the TDS signature is similar to that of TBA, the bands are more pronounced. TBA2,11BrG was expected to be less structured or having a different structure from native TBA but, on the contrary it shows to be more stable and very similar to native TBA.

To further examine the structural stability of double 8-BrdG modification, UV thermal melting analysis was conducted in dimeric quadruplex formed by the Oxytricha nova telomere repeat oligonucleotide $\left(\mathrm{G}_{4} \mathrm{~T}_{4} \mathrm{G}_{4}\right)$ [21]. This oligonucleotide forms an antiparallel dimeric quadruplex with four G-quartets. When we introduce a single 8-BrdG derivative two modifications in two different G-tetrads are produced. The modification in position 3 (syn) produced as expected a more stable G-quadruplex structure with an increased thermal stability of more than $12^{\circ} \mathrm{C}$. However, the modification in position 2 (anti) that altered the central G-tetrads produced a complete disruption of the G-quadruplex structure. $C D$ analysis showed $G_{4} T_{4} G_{4}$ and $\mathrm{G}_{4} \mathrm{~T}_{4} \mathrm{G}_{4} 3 \mathrm{BrG}$ variants with an antiparallel feature, whereas $\mathrm{G}_{4} \mathrm{~T}_{4} \mathrm{G}_{4} 2 \mathrm{BrG}$ were almost featureless, thus implying an unstructured oligonucleotide. Modification in two different and consecutive tetrads produces partly (in the case of monomeric TBA) or completely (in the case of dimeric $\mathrm{G}_{4} \mathrm{~T}_{4} \mathrm{G}_{4}$ ) disruption of the quadruplex structures, while no syn-anti switch is assumed to produce a rearrangement of the quadruplex structure.

In order to understand the increased stability of the double modification in the same tetrad we performed NMR studies of double 8-BrdG modified TBA variants.

\subsection{NMR structural characterization of TBA2,11BrG and TBA 2,6 BrG}

The analogy with the native TBA together with the well established procedures [6, 36-38] were used to identify the imino, aromatic and ribose protons of two tetrads and loops. In Table S1 and $\mathrm{S} 2$ are selected chemical shifts for TBA2,11BrG and TBA2,6BrG, respectively, are reported. ${ }^{1} \mathrm{H}$ NMR spectra of the exchangeable resonances of TBA2,6BrG and TBA2,11BrG display sharp eight hydrogen-bonded $\mathrm{G}$ imino proton resonances (11.8-12.6 ppm) indicating the formation of 
two G-tetrads as in the unmodified TBA (Fig S2). The spectra shown in Fig. S2 also display the exchangeable protons from the loop residue. All the exchangeable protons are characterized by small linewidths, confirming the presence of a folded antiparallel quadruplex structure. Downfield chemical shift variation of $\mathrm{NH}$ imino protons of the modified guanines in comparison with the unmodified TBA is in agreement with literature data [39] $(\Delta \delta=+0.32$ and $+0.37 \mathrm{ppm}$ for $\mathrm{G} 2$ and $\mathrm{G} 11$ in $\mathrm{TBA} 2,11 \mathrm{BrG}$ and $\Delta \delta=+0.21$ and $+0.25 \mathrm{ppm}$ for G2 and G6 in TBA2,6BrG).

Inter and intraresidue NOEs were identified for both the modified aptamers as previously reported by different authors for the native TBA [6, 36-38]. In particular: a) the key NOEs between the methyl of one $\mathrm{T}$ with four different imino protons allowed to identify $\mathrm{T} 9$ and G1,G6,G10 and G15 in analogy with the unmodified TBA (Fig. 3). Moreover long-range connectivities between H8G8 and ribose protons H2' and H2', of G6 and between H8 G15 with the anomeric proton of T9 were also detected (Fig. 4). These contacts are related to other NOEs between the anomeric protons of T9 and G8 with NH imino protons of the tetrad G1-G6-G10G15.; $b$ ) the key NOEs between $\mathrm{H} 2$ ' and $\mathrm{H} 2$ ' ' ribose protons of other two $\mathrm{T}$ with imino protons different to the previous ones allowed to identify T4 and T13 and G5 and G14 residues (Fig. 3). Complementary information are given by the NOEs between methyl T4 and H1', H2' and H2', of G2 and from methyl of T13 with H1', H2' and H2" of G11. All these findings allowed the G2-G5-G11-G14 tetrad to be assigned. Long-range NOE weak connectivities between methyl of T4 and methyl of T13 with G2 and G11 NH respectively were also detected for TBA2,11BrG whereas these connectivities were not observed for TBA2,6BrG. These long-range NOEs were also found in the $\mathrm{Sr}^{2+}$-TBA complex by Mao et coworkers and this suggest that these two thymines for TBA2,11BrG were not-coplanar with the $\mathrm{G}$ tetrad and the methyl groups are oriented edgewise towards the quadruplex core [39].

The glycosidic angles for Gs in the tetrads, with the exception for the G residues missing of the aromatic $\mathrm{H} 8$ protons, were determined by the intensities of the NOEs interactions between $\mathrm{H} 8$ $\mathrm{H} 1$ ' and $\mathrm{H} 8-\mathrm{H} 2$ '/H2' of the $\mathrm{G}$ residues. The alternation syn-anti in the tetrads is respected as in the native TBA for both modified derivatives (Fig. 4). These findings, together with the CD data, allowed us to conclude that both modified have a similar topology as the native TBA with a difference at the level of the TT loop for TBA2,11BrG.

Melting experiments performed in the above modified TBAs and in TBA5BrG confirm the UV and CD data (Fig. S3). After the melting experiments, the same spectra were obtained cooling the samples at the temperature of $25^{\circ} \mathrm{C}$ and $5^{\circ} \mathrm{C}$.

In conclusion, the $8 \mathrm{BrGs}$ need to flip from syn to anti in both modified TBA to assist the folding process. This process needs some energy requirement. This happens also for other aptamers previously studied [23]. This causes for TBA2,6 BrG a penalization in terms of stability due to the steric hindrance of the bromine in comparison with the native TBA. G2 and G6 units belong 
to two different tetrads in the structure of the aptamer and experiment a different local structural environment in terms of loops. G2 and G6 are close to TT and TGT loops. After the sequential assignment we observed that, in the case of $\mathrm{TBA} 2,6 \mathrm{BrG}$, the imino and aromatic regions show weak signals due to minor conformations present in solution (Fig. 4). Strangely for the TBA2,11BrG, we observed a slight increasing of the stability in comparison with the native TBA. G2 and G11 belong to the same tetrad in the structure and experience an equal local structural environment in terms of loops. G2 and G11 are symmetrically positioned and close to TT loops with the methyl groups oriented in a different way compared with the native TBA. This results in a more favorable assistance in the folding arrangement.

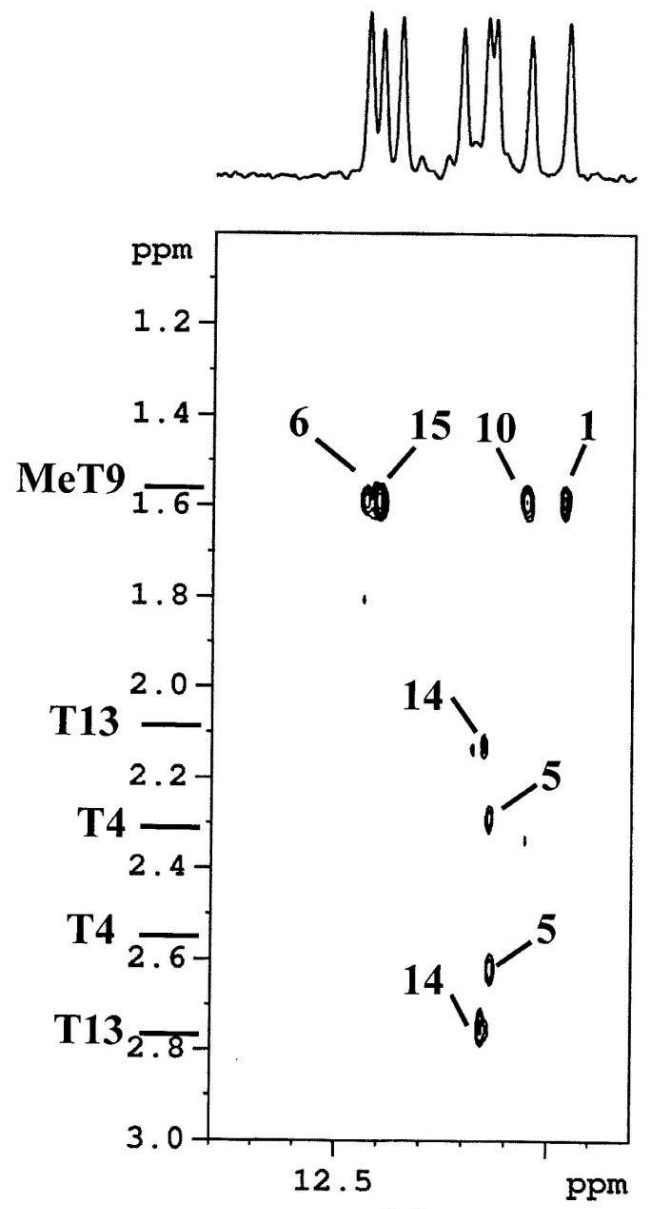

(a)

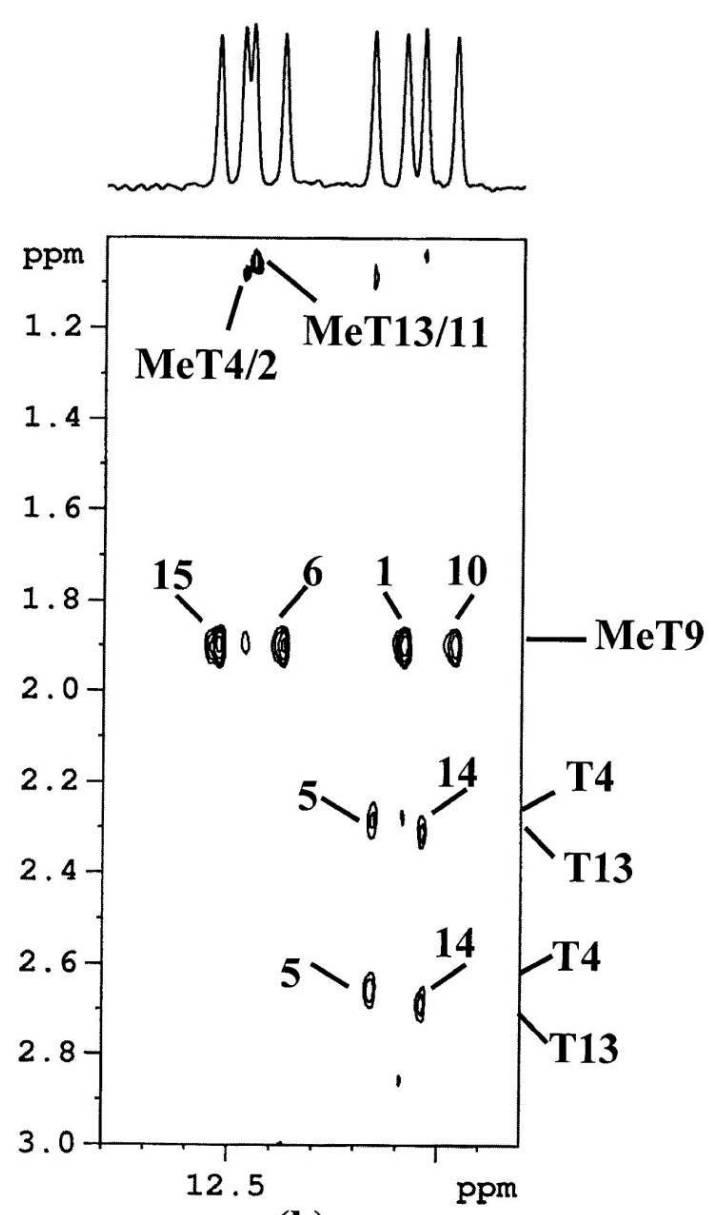

(b)

Fig. 3. Selected region of NH imino protons in NOESY spectra showing cross peaks of methyl of T9 and H2' and H2', resonances of T4 and T13. Assignments are reported in the figure. (a) TBA2,6BrG and (b) TBA2,11BrG, in $5 \mathrm{mM} \mathrm{KCl}, 10 \mathrm{mM} \mathrm{K}{ }_{2} \mathrm{HPO}_{4} / \mathrm{KH}_{2} \mathrm{PO}_{4}$ phosphate buffer, $\mathrm{pH} 6.9, \mathrm{~T}=5^{\circ} \mathrm{C}$. 


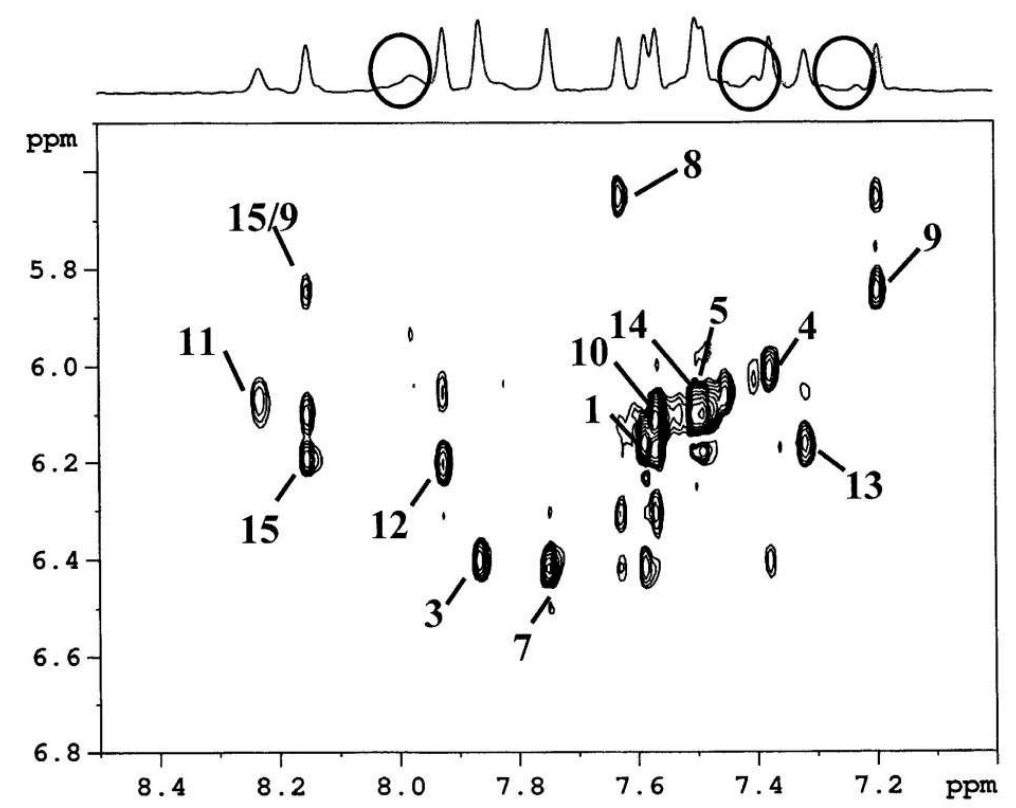

(a)

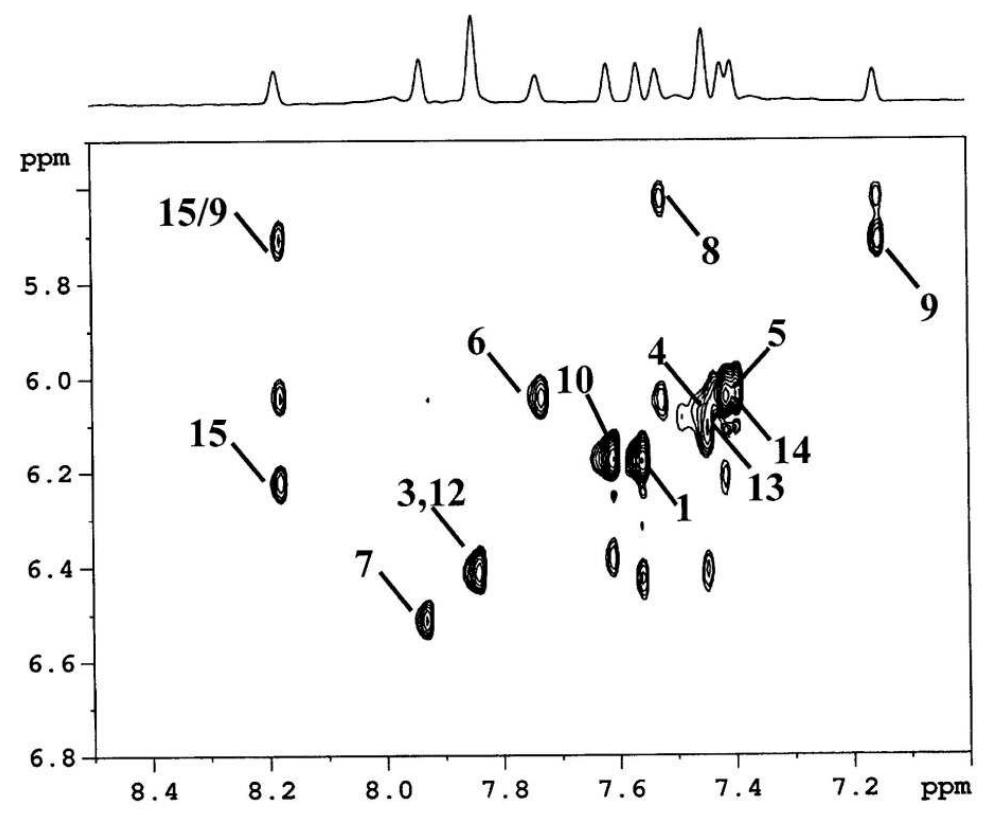

(b)

Fig. 4. Expanded region of NOESY spectra showing aromatic protons and anomeric protons. Assignments are reported in the figure. (a) $\mathrm{TBA} 2,6 \mathrm{BrG}$ and (b) $\mathrm{TBA} 2,11 \mathrm{BrG}$, in $5 \mathrm{mM} \mathrm{KCl}$, 
$10 \mathrm{mM} \mathrm{K} \mathrm{HPO}_{4} / \mathrm{KH}_{2} \mathrm{PO}_{4}$ phosphate buffer, $\mathrm{pH} 6.9, \mathrm{~T}=5^{\circ} \mathrm{C}$. Minor conformation presents in solution for $\mathrm{TBA} 2,6 \mathrm{BrG}$ are indicated with circles on the projection.

\subsection{Thrombin binding affinity}

We studied the complex formation between thrombin and the 8-Br-dG TBA variants by electrophoresis mobility shift assay (EMSA). Single substitutions facilitates the complex formation with thrombin at lower ratio however at 1:10 the complex formation is the similar to native TBA. On the contrary $8-\mathrm{Br}-\mathrm{dG}$ double substitutions in the TBA produced a decrease in the affinity of the TBA variants for thrombin. From these experiments we can conclude that one single modification of guanine by $8-\mathrm{BrdG}$ is allowed for thrombin recognition but double modification is detrimental for thrombin binding and it confirms that thrombin binding is not dependent of the thermal stability of TBA variants as shown by other authors $[17,19]$.

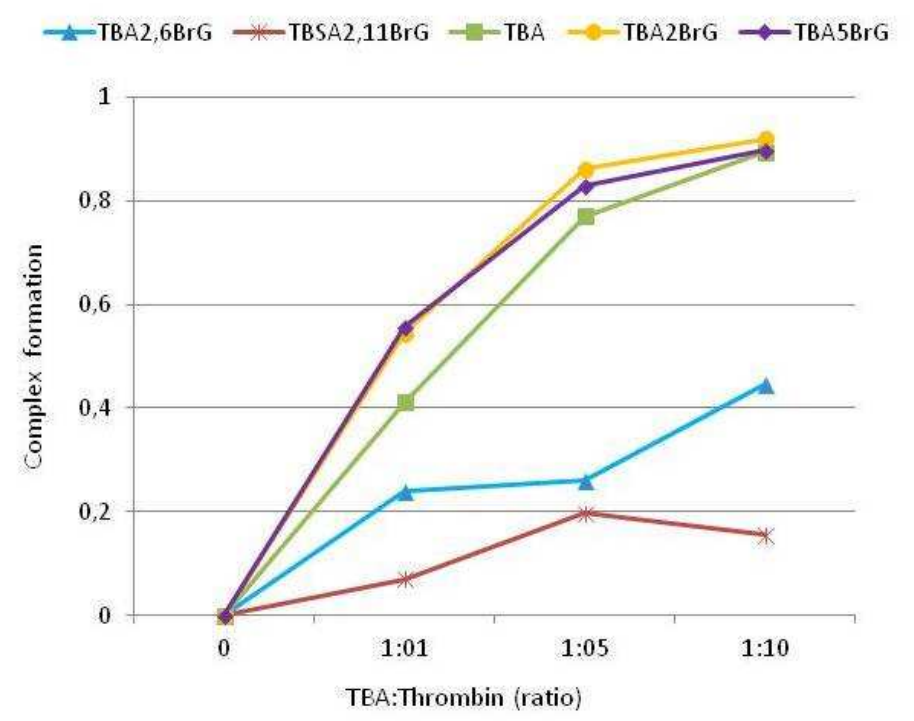

Fig. 5. EMSA assay of complexes between thrombin and TBA variant in in $100 \mathrm{mM}$ Tris $\mathrm{pH}$ 7.4, $50 \mathrm{mM}$ AcOH, $5 \mathrm{mM}$ EDTA, $12.5 \mathrm{mM} \mathrm{Mg}(\mathrm{OAc})_{2}$.

\section{Conclusions}

In conclusion, we showed that chemical modifications could provide important information about TBA stability and protein-nucleic acids binding affinity. The substitutions of loop positions with GNA T affect the TBA stability except for single modification in T7 position. However, when the T9 or T4 positions are modified the resulting TBA are much less stable. Single L-thymidine substitutions produced also destabilization of TBA but compared with 
GNAT a smaller destabilization in positions 3, 4 and 7 is observed, indicating that this modification is more permissive than GNA.

In addition, the presence of single $8-\mathrm{BrdG}$ in the tetrads, that have preference to adopt a syn glycosidic conformation is the major responsible for the correct tetrad formation and subsequent TBA stability. Nevertheless, double $8-B r d G$ modification in anti positions of different tetrads produce a conformational flip from syn to anti conformation of 8-Br-dG to favor loop-tetrad interaction and preserve the overall TBA stability. EMSA experiments showed that double 8BrdG produced TBA variants with less thrombin affinities than single modified.

\section{Acknowledgements}

We acknowledge funding from the Spanish Ministry of Economy (MICINN) (CTQ2014-52588R, CTQ2014-61758-EXP, CTQ2011-15203-E, CTQ2012-35360, CTQ2015-66254-C2-2-P) and the Generalitat de Catalunya (2014SGR187). PP acknowledges a contract from project CTQ2011-15203-E. CIBER-BBN is an initiative funded by the VI National R\&D\&I Plan 2008-

2011, Iniciativa Ingenio 2010, Consolider Program, CIBER Actions and financed by the Instituto de Salud Carlos III with assistance from the European Regional Development Fund.

\section{Appendix A. Supplementary data}

Supplementary data to this article can be found online at

\section{References}

[1] S. Burge, G.N. Parkinson, P. Hazel, A.K. Todd, S. Neidle, Quadruplex DNA: sequence, topology and structure, Nucleic Acids Res. 34 (2006) 5402-5415.

[2] M. L. Bochman, K. Paeschke, V. A. Zakian, DNA secondary structures: stability and function of G-quadruplex structures, Nature Reviews Genetics 13 (2012) 770-780.

[3] A. Aviño, C. Fàbrega, M. Tintoré, R. Eritja, Thrombin binding aptamer, more than a simple aptamer: chemically modified derivatives and biomedical applications, Curr. Pharm. Des. 18 (2012) 2036-2047.

[4] D. Musumeci, D. Montesarchio, Polyvalent nucleic acid aptamers and modulation of their activity: a focus on the thrombin binding aptamer, Pharmacol. Ther. 136 (2012) 202-215.

[5] J.A. Kelly, J. Feigon, T.O. Yeates, Reconciliation of the X-ray and NMR structures of the thrombin-binding aptamer d(GGTTGGTGTGGTTGG) J. Mol. Biol. 256 (1996) 417-422.

[6] R.F. Macaya, P. Schultze, F.W. Smith, J.A. Roe, J. Feigon, Thrombin-binding DNA aptamer forms a unimolecular quadruplex structure in solution, Proc. Nat. Acad. Sci. U.S.A. 90 (1993) 3745-3749. 
[7] K. Padmanabhan, A. Tulinsky, An ambiguous structure of a DNA 15-mer thrombin complex, Acta Cryst. D52 (1996) 272-282.

[8] I. Russo Krauss, A. Merlino, C. Giancola, A. Randazzo, L.Mazzarella, F. Sica, Thrombinaptamer recognition: a revealed ambiguity, Nucleic Acids Res. 39 (2011) 7858-7867.

[9] A. Aviñó, G. Portella, R. Ferreira, R. Gargallo, S. Mazzini, V. Gabelica, M. Orozco, R. Eritja, Specific loop modifications of the thrombin-binding aptamer trigger the formation of parallel structures, FEBS J. 281 (2014) 1085-1099.

[10] A.Virno, A. Randazzo, C. Giancola, M. Bucci, G. Cirino, L. Mayol, A novel thrombin binding aptamer containing a G-LNA residue. Bioorg. Med. Chem. 15 (2007) 5710-5718.

[11] L. Bonifacio, F. C. Church, M. B. Jarstfer, Effect of locked-nucleic acid on a biologically active G-quadruplex. A structure-activity relationship of the thrombin aptamer, Int. J. Mol. Sci. 9 (2008) 422-433.

[12] A. Pasternak, F.J. Hernandez, L.M. Rasmussen, B. Vester, J. Wengel Improved thrombin binding aptamer by incorporation of a single unlocked nucleic acid monomer Nucleic Acids Res. 39 (2011) 1155-1164.

[13]C.G. Peng, M.J. Damha, G-quadruplex induced stabilization by 2'-deoxy-2'-fluoro-Darabinonucleic acids (2'F-ANA), Nucleic Acids Res. 35 (2007) 4977-4988.

[14] G.-X. He, S.H. Krawczyk, S. Swaminathan, S.G. Regan, J.P. Dougherty, T. Terhorst, V.S. Law, L.C. Griffin, S. Coutrè, N. Bischofberger, $\mathrm{N}^{2}$ - and $\mathrm{C}^{8}$-Substituted oligodeoxynucleotides with enhanced thrombin inhibitory activity in vitro and in vivo J. Med. Chem. 41 (1998) 22342242.

[15] M. Khati, The future of aptamers in medicine J Clin Pathol 63 (2010) 480-487.

[16] V. Dapic, V. Abdomerovic, R. Marrington, J. Peberdy, A. Rodger, J.O. Trent, P.J. Bates, Biophysical and biological properties of quadruplex oligodeoxyribonucleotides Nucleic Acids. Res. 31 (2003) 2097-2107.

[17] A. Virgilio, L.Petraccone, V. Vellecco, M. Bucci, M.Varra, C. Irace, R. Santamaria, A. Pepe, L. Mayol, V. Esposito,A. Galeone, Site-specific replacement of the thymine methyl group by fluorine in thrombin binding aptamer significantly improves structural stability and anticoagulant activity Nucleic Acids Res. 43 (2015) 10602-10611.

[18] N. Zhang, T. Bing ,X. Liu , C.Qi , L. Shen., L. Wang, D. Shangguan, Cytotoxicity of guanine-based degradation products contributes to the antiproliferative activity of guanine-rich oligonucleotides. Chem. Sci. 6 (2015) 3831-3838.

[19] M. Scuotto, E. Rivieccio, A. Varone, D. Corda, M. Bucci, V. Vellecco, G. Cirino, A. Virgilio, V. Esposito, A. Galeone, N. Borbone, M. Varra, L. Mayol, Site specific replacements of a single loop nucleoside with a dibenzyl linker may switch the activity of TBA from anticoagulant to antiproliferative. Nucleic Acids Res. 43 (2015) 7702-7716. 
[20] M. Jarczewska, Ł.Górski, , E. Malinowska, Application of DNA aptamers as sensing layers for electrochemical detection of potassium ions, Sensors, Actuators B: Chemical 226(2016) 3743.

[21] P. Schultze, N. V. Hud, F. W. Smith, J. Feigon, The effect of sodium, potassium and ammonium ions on the conformation of the dimeric quadruplex formed by the Oxytricha nova telomere repeat oligonucleotide d(G4T4G4) Nucleic. Acids Res. 27 (1999) 3018-3028.

[22] L. Zhang, E. Meggers, A simple glycol nucleic acid, J. Am. Chem. Soc. 127 (2005) 4174 4175.

[23] P. L. T. Tran, R. Moriyama, A. Maruyama, B. Rayner, J.L. Mergny, A mirror-image tetramolecular DNA quadruplex Chem. Commun. 47 (2011) 5437-5439.

[24] H. Urata, T.Kumashiro, T. Kawahata, T.Otake, M. Akagi, Anti-HIV-1 activity and mode of action of mirror image oligodeoxynucleotide analogue of Zintevir, Biochem. Biophys. Res. Commun. 313 (2004) 55-61.

[25] A. Virgilio, M. Varra, M. Scuotto, A. Capuozzo, C. Irace, L. Mayol, V. Esposito, A.Galeone, Expanding the potential of G-quadruplex structures: formation of a heterochiral TBA analogue, Chembiochem 15 (2014) 652-655.

[26] B. Cai, X. Yang, L. Sun, X. Fan, L. Li, H. Jin, Y. Wu, Z. Guan, L. Zhang, L. Zhang, Z. Yang Stability and bioactivity of thrombin binding aptamers modified with D-/L-isothymidine in the loop regions Org. Biomol. Chem. 12 (2014) 8866-8876.

[27] S. Goji, J. Matsui, Direct detection of thrombin binding to 8-bromodeoxyguanosinemodified aptamer: effects of modification on affinity and kinetics, J. Nucleic Acids 2011 (2011) 316079.

[28] L. Petraccone, I. Duro, A. Randazzo, A. Virno, L. Mayol, C. Giancola, Biophysical properties of quadruplexes containing two or three 8-bromodeoxyguanosine residues, Nucleosides, Nucleotides, Nucleic Acids, 26 (2007) 669-674.

[29] E. Dias, J. L. Battiste, J. R. Williamson, Chemical probe for glycosidic conformation in telomeric DNAs, J. Am. Chem. Soc. 116 (1997) 4479-4480.

[30] J.D. Puglisi, I. Tinoco Absorbance melting curves of RNA Methods Enzymol 180 (1989) 304-325.

[31] J.L. Mergny, J. Li, L. Lacroix, S. Amrane, J. B. Chaires, Thermal difference spectra: a specific signature for nucleic acid structures Nucleic Acids Res. 33 (2005) e138.

[32] A. Bax, D.G. Davis, MLEV-17-based two-dimensional homonuclear magnetization transfer spectroscopy, J. Magn. Reson. 1969 (65) (1985) 355-360.

[33] T.D. Goddard, D.G. Kneller, SPARKY 3, University of California, San Francisco, USA, 2004.

[34] T.B. Jensen, J.R. Henriksen, B.E. Rasmussen, L.M. Rasmussen, T.L Andresen, J. Wengel, A. Pasternak, Thermodynamic and biological evaluation of a thrombin binding aptamer 
modified with several unlocked nucleic acid (UNA) monomers and a 2'-C-piperazino-UNA monomer, Bioorg. Med. Chem. 19 (2011) 4739-4745.

[35] H. Saneyoshi, S. Mazzini, A. Aviñó, G. Portella, C. González, M. Orozco, V. E. Marquez, R. Eritja, Conformationally rigid nucleoside probes help understand the role of sugar pucker and nucleobase orientation in the thrombin-binding aptamer Nucleic Acids Res. 37 (2009) 55895601.

[36] K.W. Wang, S. McCurdy, R.G. Shea, S. Swaminathan, P.H. Bolton, A DNA aptamer which binds to and inhibits thrombin exhibits a new structural motif for DNA, Biochemistry 32 (1993) 1899-1904.

[37] K.Y. Wang, S.H. Krawczyk, N. Bischofberger, S. Swaminathan, P. H. Bolton, The tertiary structure of a DNA aptamer which binds to and inhibits thrombin determines activity, Biochemistry 32 (1993) 11285-11292.

[38] P.Schultze, R.F. Macaya, J. Feigon, Three-dimensional solution structure of the thrombinbinding DNA apatamer d(GGTTGGTGTGGTTGG), J. Mol. Biol., 235, (1994), 1532-1547.

[39] C.J. Lech, J.K. Cheow Lim, J.M. Wen Lim, S. Amrane, B. Heddi, A.T. Phan, Effects of site-specific guanine C-8 modifications on an intramolecular DNA G-quadruplex, Biophys. J. 101 (2011) 1987-1998.

[40] X. Mao, L.A. Marky, W. H. Gmeiner, NMR structure of the thrombin-binding DNA aptamer stabilized by Sr2+, J. Biomol. Struct. Dyn. 22 (2004), 25-33. 


\section{Supplementary Content}

Fig. S1. Thermal difference spectra of a) TBAs modified with $8 \mathrm{Br}-\mathrm{dG}$ b) TBAs modified with GNAT c) TBAs modified with LT and d) $\mathrm{G}_{4} \mathrm{~T}_{4} \mathrm{G}_{4}$ modified with $8 \mathrm{Br}-\mathrm{dG}$

a

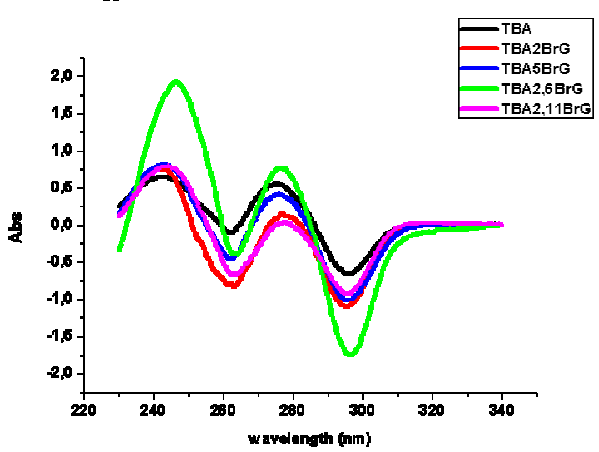

c

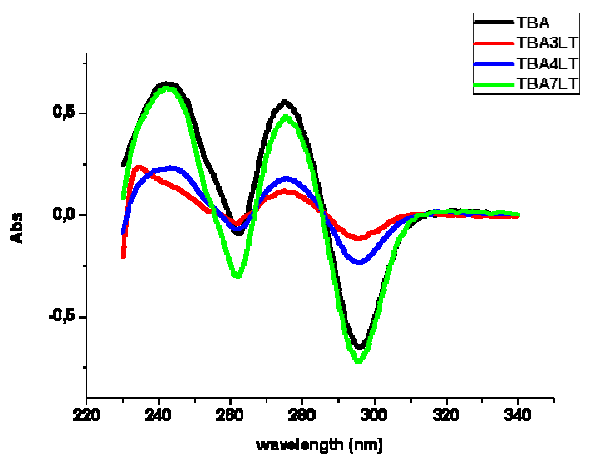

b

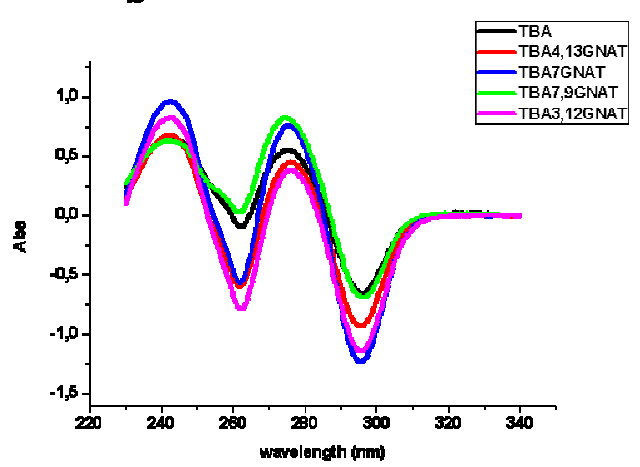

d

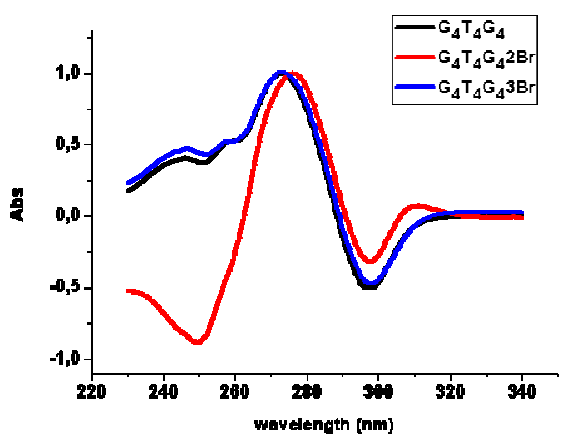


Table S1 Proton chemical shift of TBA2,11BrG in $5 \mathrm{mM} \mathrm{KCl}, 10 \mathrm{mM} \mathrm{K} \mathrm{HPO}_{4} / \mathrm{KH}_{2} \mathrm{PO}_{4}$ phosphate buffer, $\mathrm{pH} 6.9, \mathrm{~T}=5^{\circ} \mathrm{C}$.

\begin{tabular}{|l|l|l|l|l|l|l|}
\hline Base & H8/H6 & H1' & H2' & H2' & MeT & NH \\
\hline G1 & 7.57 & 6.16 & 3.01 & 3.01 & - & 12.09 \\
\hline G2 $^{\text {Br }}$ & - & 6.39 & 2.84 & 2.26 & - & 12.47 \\
\hline T3 & 7.83 & 6.39 & 2.69 & 2.28 & 1.93 & 11.48 \\
\hline T4 & 7.45 & 6.05 & 2.27 & 2.64 & 1.07 & 11.57 \\
\hline G5 & 7.40 & 6.01 & 3.44 & 2.82 & - & 12.17 \\
\hline G6 & 7.74 & 6.03 & 2.86 & 2.61 & - & 12.39 \\
\hline T7 & 7.94 & 6.49 & 2.53 & 2.60 & 1.97 & 11.48 \\
\hline G8 & 7.53 & 5.61 & 1.90 & 2.24 & - & 10.63 \\
\hline T9 & 7.16 & 5.69 & 2.03 & 2.48 & 1.89 & 10.28 \\
\hline G10 & 7.62 & 6.15 & 3.70 & 3.17 & - & 11.97 \\
\hline G11 & - & 6.39 & 3.01 & 2.81 & - & 12.45 \\
\hline T12 & 7.85 & 6.37 & 2.26 & 2.69 & 1.96 & 11.48 \\
\hline T13 & 7.45 & 6.40 & 2.28 & 2.69 & 1.03 & 11.57 \\
\hline G14 & 7.42 & 6.03 & 3.60 & 2.88 & - & 12.04 \\
\hline G15 & 8.19 & 6.20 & 2.71 & 2.45 & - & 12.53 \\
\hline
\end{tabular}

${ }^{a} \mathrm{H} 1$ ' T9 experiments a chemical exchange with another $\mathrm{H} 1$ ' T9 resonating at $5.80 \mathrm{ppm}$ 
Table S2 Proton chemical shift of TBA2,6BrG in $5 \mathrm{mM} \mathrm{KCl}, 10 \mathrm{mM} \mathrm{K} \mathrm{K}_{2} \mathrm{HPO}_{4} / \mathrm{KH}_{2} \mathrm{PO}_{4}$ phosphate buffer, $\mathrm{pH} 6.9, \mathrm{~T}=5^{\circ} \mathrm{C}$.

\begin{tabular}{|l|l|l|l|l|l|l|}
\hline Base & H8/H6 & H1' & H2' & H2' & MeT & NH \\
\hline G1 & 7.58 & 6.16 & 3.13 & 3.13 & - & 11.96 \\
\hline G2 $^{\text {Br }}$ & - & 6.41 & 2.92 & 2.74 & - & 12.35 \\
\hline T3 & 7.86 & 6.40 & 2.25 & 2.72 & 1.96 & 11.28 \\
\hline T4 & 7.37 & 6.00 & 2.25 & 2.59 & 1.09 & 11.40 \\
\hline G5 & 7.49 & 6.08 & 3.52 & 2.93 & - & 12.13 \\
\hline G6 $^{\text {Br }}$ & - & 6.30 & 3.13 & 2.68 & - & 12.43 \\
\hline T7 & 7.74 & 6.40 & 2.51 & 2.57 & 1.95 & 11.28 \\
\hline G8 & 7.62 & 5.64 & 1.99 & 2.36 & - & 10.75 \\
\hline T9 & 7.19 & $5.83^{\mathrm{a}}$ & 1.97 & 2.34 & 1.58 & 10.30 \\
\hline G10 & 7.56 & 6.09 & 3.69 & 2.93 & - & 12.05 \\
\hline G11 & 8.23 & 6.07 & 3.00 & 2.34 & - & 12.21 \\
\hline T12 & 7.92 & 6.19 & 2.23 & 2.34 & 1.99 & 11.28 \\
\hline T13 & 7.31 & 6.15 & 2.12 & 2.73 & 0.96 & 11.40 \\
\hline G14 & 7.49 & 6.08 & 3.52 & 2.97 & - & 12.14 \\
\hline G15 & 8.15 & 6.17 & 2.72 & 2.43 & - & 12.40 \\
\hline
\end{tabular}

${ }^{a} \mathrm{H} 1$ ' T9 experiments a chemical exchange with another H1' T9 resonating at $5.75 \mathrm{ppm}$ 
Fig. S2. Imino proton NMR spectra for (a) unmodified TBA, (b) TBA2,6BrG and (c) TBA2,11BrG in $5 \mathrm{mM} \mathrm{KCl}, 10 \mathrm{mM} \mathrm{K} \mathrm{HPO}_{4} / \mathrm{KH}_{2} \mathrm{PO}_{4}$ phosphate buffer, $\mathrm{pH} 6.9, \mathrm{~T}=5^{\circ} \mathrm{C}$.

(c)

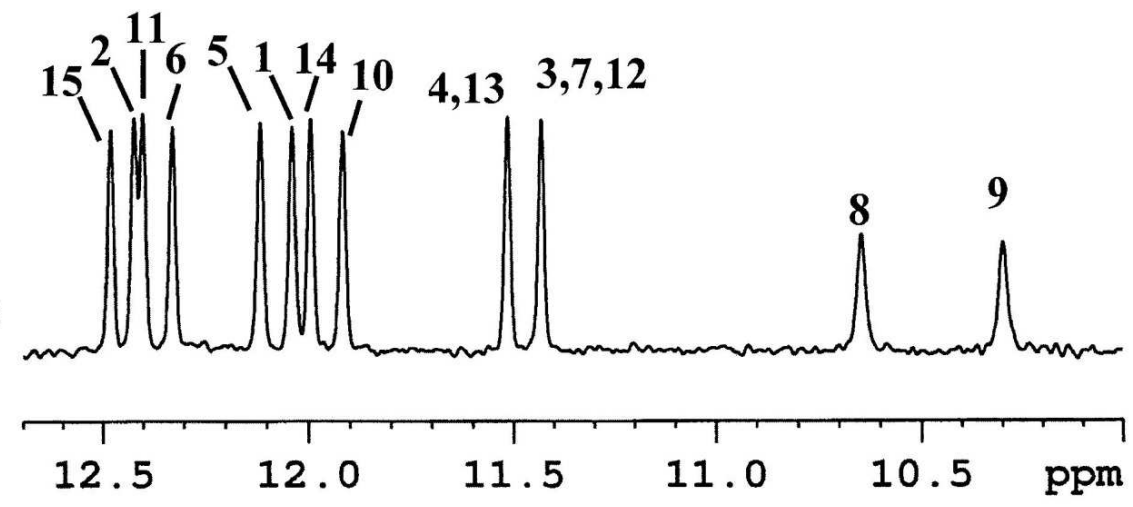

(b)

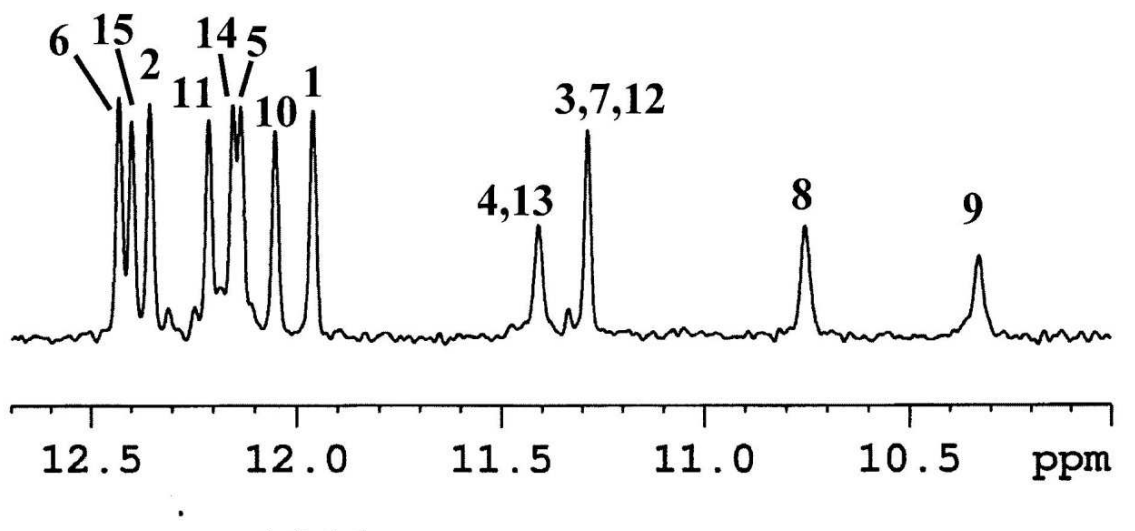

(a)

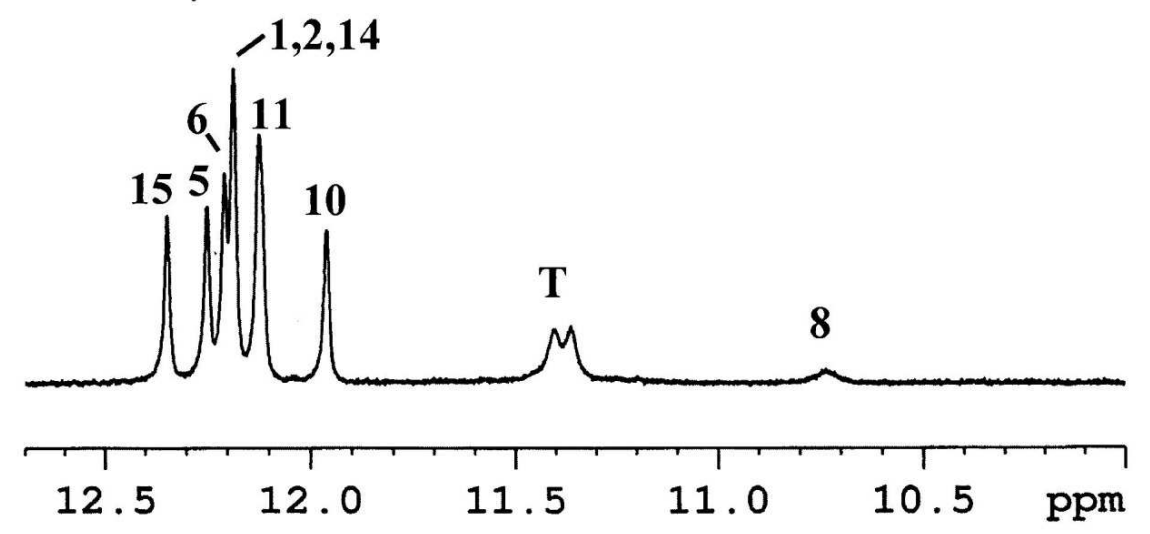


Fig. S3. Imino proton region of a) $\mathrm{TBA} 2,11 \mathrm{BrG}$ b) $\mathrm{TBA} 2,6 \mathrm{BrG}$ and c) $\mathrm{TBA} 5 \mathrm{BrG}$

a

$51^{\circ} \mathrm{C}$

$45^{\circ} \mathrm{C}$ _ N N N

$35^{\circ} \mathrm{C}$ _allth

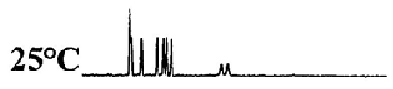

$15^{\circ} \mathrm{C}$ HUH L L

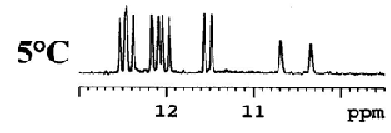

b

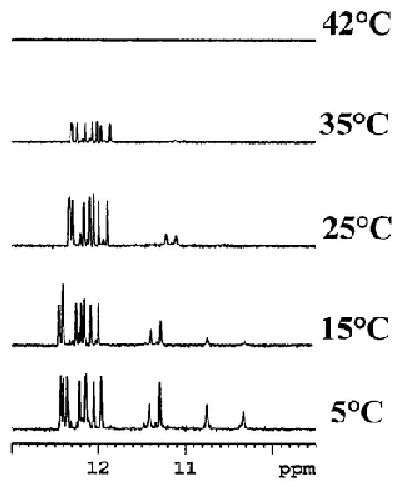

$c$

$54 \circ$
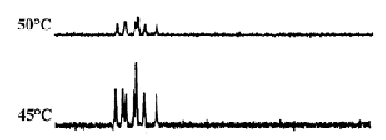

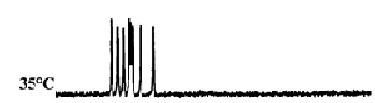
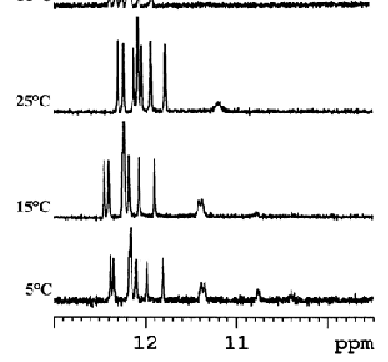
Table 1. Sequence, melting temperature $\left(T_{m}\right)$ and mass spectra of $T B A$ and $\mathrm{G}_{4} \mathrm{~T}_{4} \mathrm{G}_{4}$ derivatives used in this study. $\mathrm{T}^{\mathrm{L}}:$ L-thymidine, $\mathrm{T}^{\mathrm{N}}:(S)$-GNA-T, $\mathrm{G}^{\mathrm{Br}}: 8-\mathrm{Br}-2$ '-deoxyguanosine.

\begin{tabular}{|c|c|c|c|c|c|}
\hline Name & Sequence & $T_{m}{ }^{\mathrm{a}}\left({ }^{\circ} \mathrm{C}\right)$ & $\Delta T_{m}$ & $\mathrm{M}_{\text {calc }}$ & $\mathrm{M}_{\text {found }}$ \\
\hline TBA & GGTTGGTGTGGTTGG & 49.6 & - & 4726.0 & 4726.6 \\
\hline TBA4GNAT & GGTT $^{\mathrm{N}}$ GGTGTGGTTGG & 36.9 & -12.7 & 4684.4 & 4682.8 \\
\hline TBA7GNAT & GGTTGGT $^{\mathrm{N}}$ GTGGTTGG & 54.8 & +5.2 & 4684.4 & 4686.4 \\
\hline TBA9GNAT & GGTTGGTGT $^{\mathrm{N}}$ GGTTGG & 40.1 & -9.5 & 4684.4 & 4683.8 \\
\hline TBA7,9GNAT & GGTTGGT $^{\mathrm{N}} \mathrm{GT}^{\mathrm{N}}$ GGTTGG & 38.6 & -11 & 4642.2 & 4643.7 \\
\hline TBA3,12GNAT & GGT $^{\mathrm{N}}$ TGGTGTGGT $^{\mathrm{N}}$ TGG & 47.1 & -2.5 & 4642.2 & 4644.7 \\
\hline TBA4,13GNAT & GGTT $^{\mathrm{N}}$ GGTGTGGTT $^{\mathrm{N}}$ GG & 37.5 & -12.1 & 4642.2 & 4644.6 \\
\hline TBA7LT & GGTTGGT $^{\mathrm{L}}$ GTGGTTGG & 48.9 & -0.7 & 4726.0 & 4726.1 \\
\hline TBA4LT & GGTT $^{\mathrm{L}}$ GGTGTGGTTGG & 46.7 & -2.9 & 4726.0 & 4729.3 \\
\hline TBA3LT & GGT $^{\mathrm{L}} \mathrm{T}^{\mathrm{L}}$ GGTGTGGTTGG & 45.5 & -4.1 & 4726.0 & 4729.3 \\
\hline TBA2BrG & GG $^{\mathrm{Br}}$ TTGGTGTGGTTGG & 47.1 & -2.5 & 4804.9 & 4802.5 \\
\hline TBA5BrG & GGTTG $^{\mathrm{Br}}$ GTGTGGTTGG & 56.9 & +7.3 & 4804.9 & 4803.6 \\
\hline TBA2,11BrG & GG $^{\mathrm{Br}}$ TTGGGTGTGG ${ }^{\mathrm{Br}}$ TTGG & 53.2 & +3.6 & 4883.8 & 4480.8 \\
\hline TBA2,6BrG & GG $^{\mathrm{Br}} \mathrm{TTGG}^{\mathrm{Br}}$ TGTGGTTGG & 40.8 & -8.8 & 4883.8 & 4885.1 \\
\hline $\mathrm{G}_{4} \mathrm{~T}_{4} \mathrm{G}_{4}$ & GGGGTTTTGGGG & 59 & - & 3786.4 & 3785.2 \\
\hline $\mathrm{G}_{4} \mathrm{~T}_{4} \mathrm{G}_{4} 2 \mathrm{BrG}$ & GG $^{\mathrm{Br}}$ GGTTTTGGGG & - & - & 3865.3 & 3864.4 \\
\hline $\mathrm{G}_{4} \mathrm{~T}_{4} \mathrm{G}_{4} 3 \mathrm{BrG}$ & GGG $^{\mathrm{Br}}$ GTTTTGGGG & 71.3 & +12.3 & 3865.3 & 3864.4 \\
\hline
\end{tabular}

${ }^{\mathrm{a}} 10 \mathrm{mM}$ sodium cacodilate, $100 \mathrm{mM} \mathrm{KCl} \mathrm{pH} \mathrm{7.} \mathrm{Uncertainty} 0.5^{\circ} \mathrm{C}$ 
a)

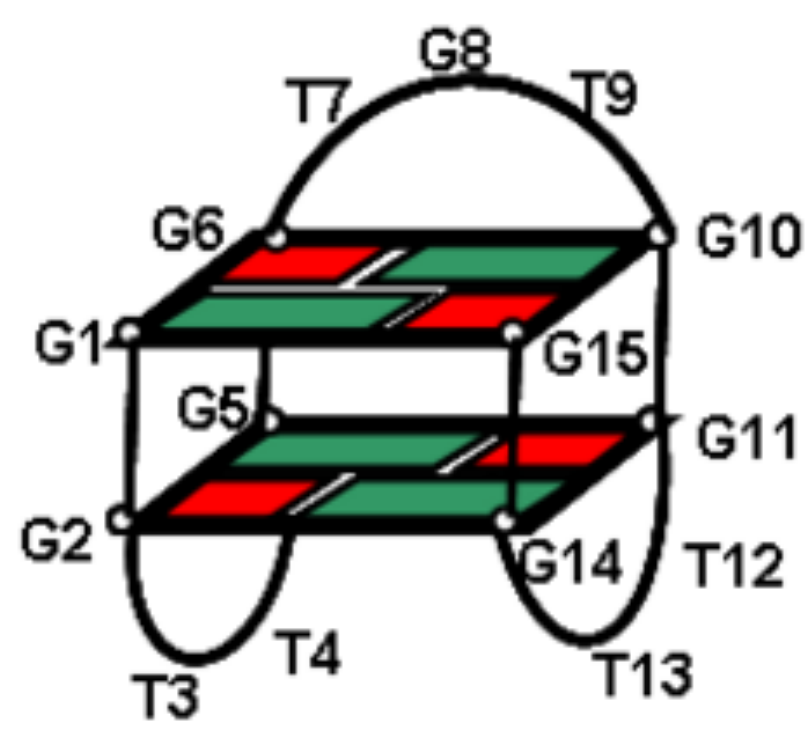

b)

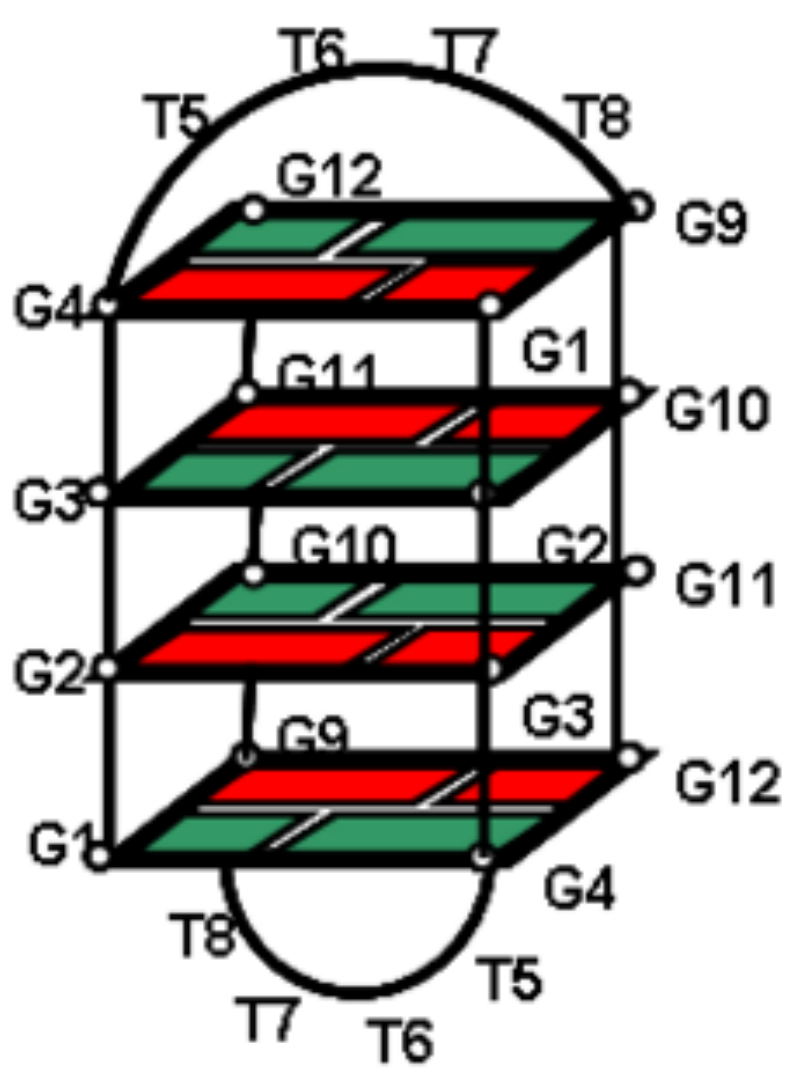

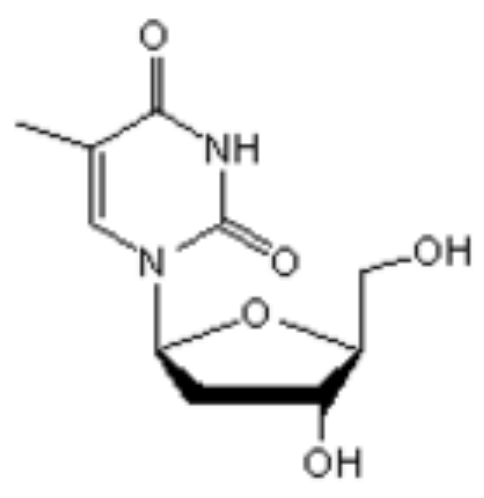

L-Thymidine

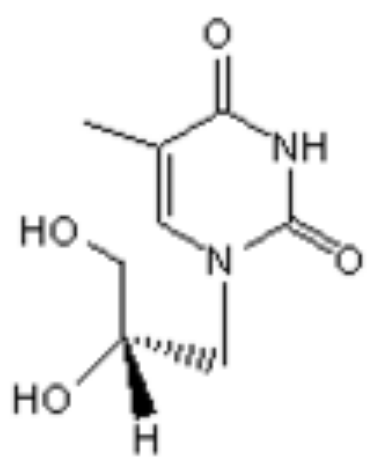

(S)-T-GNA

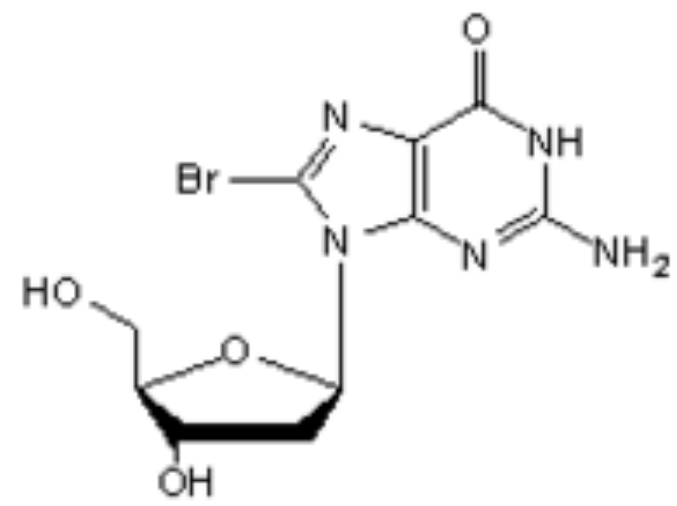

8-Bromo-dG 


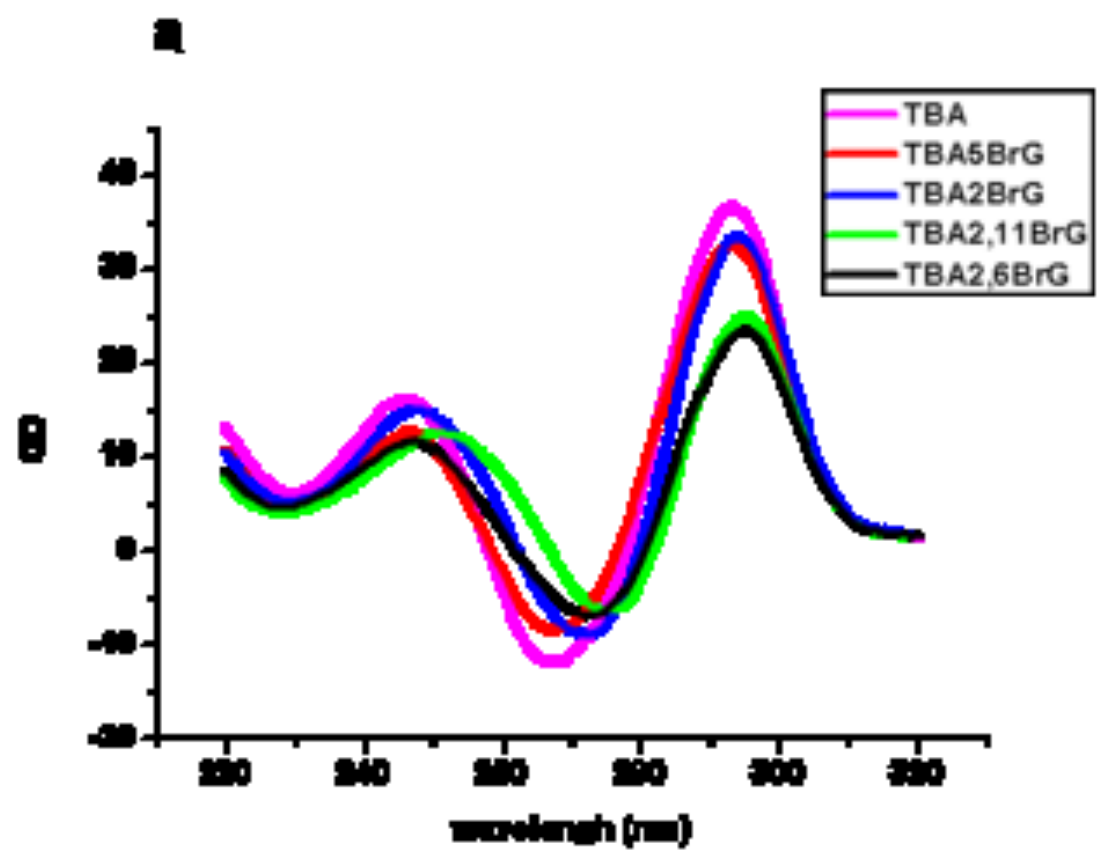

$E$

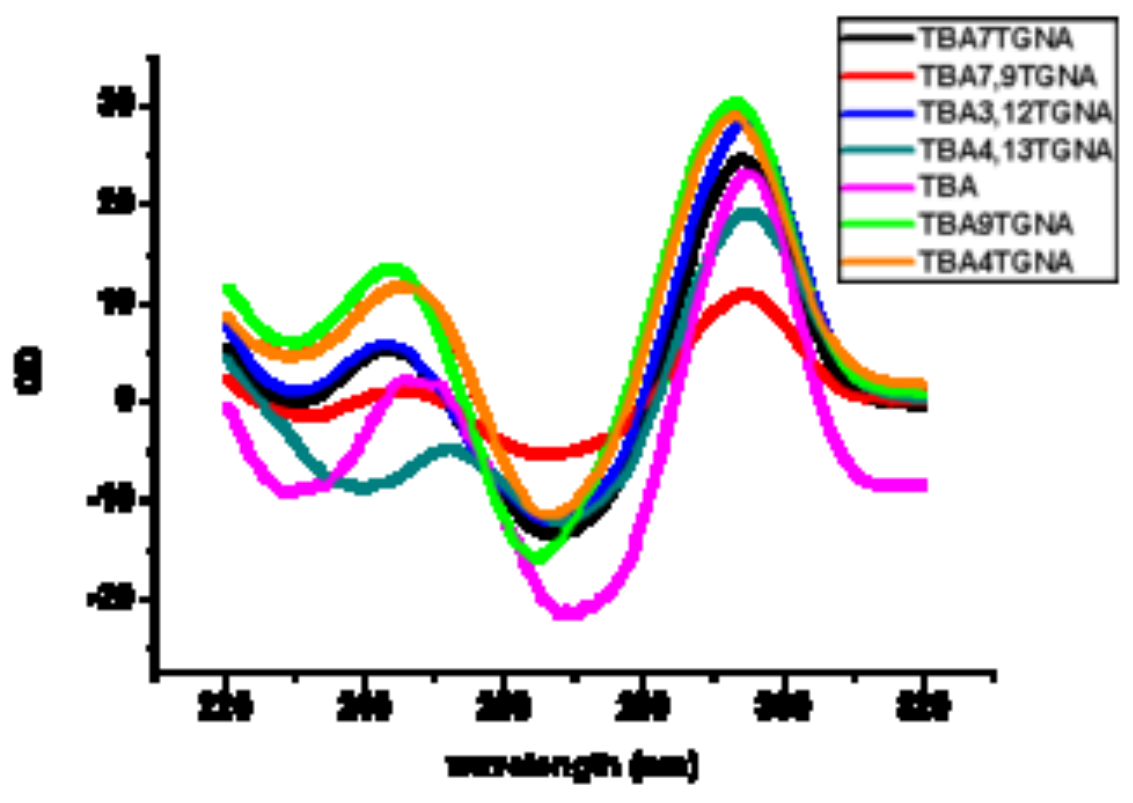

b

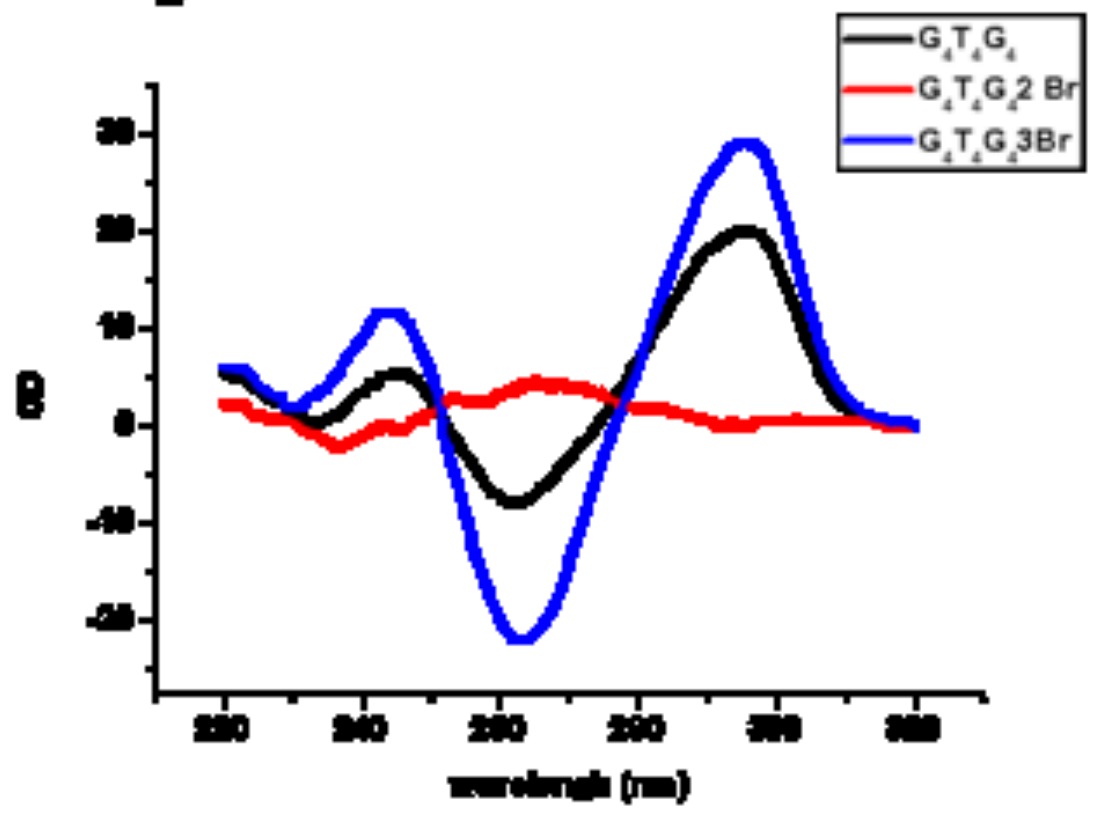

d

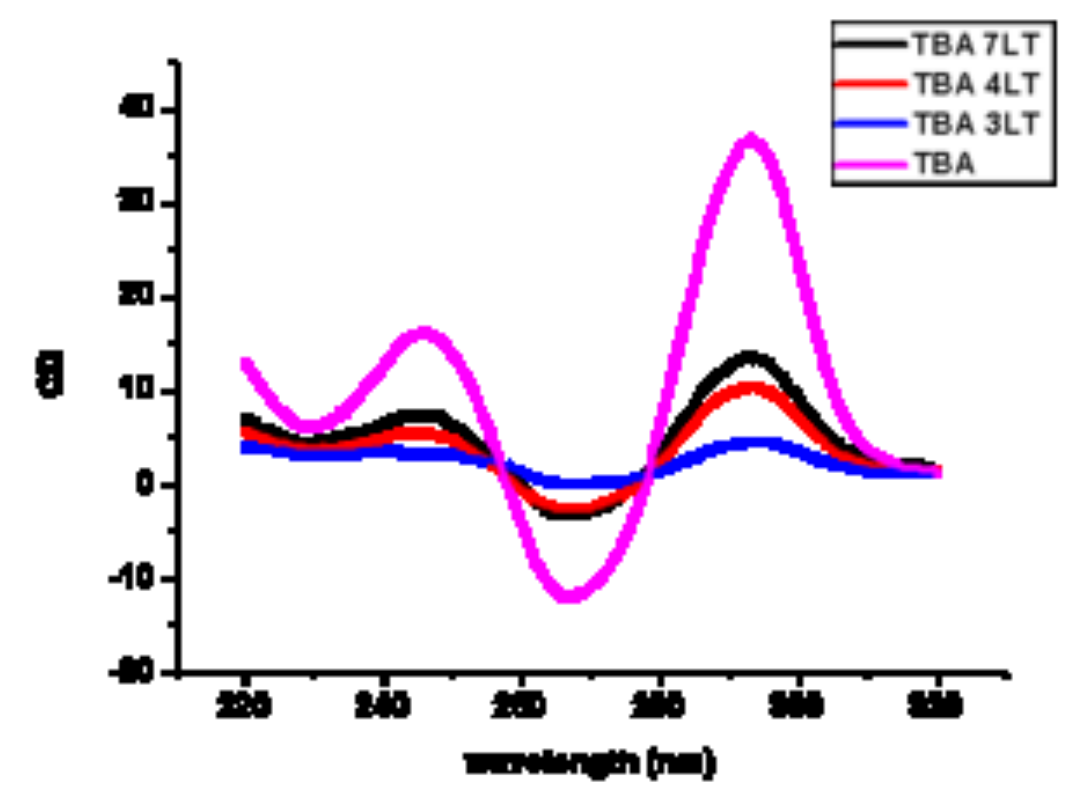




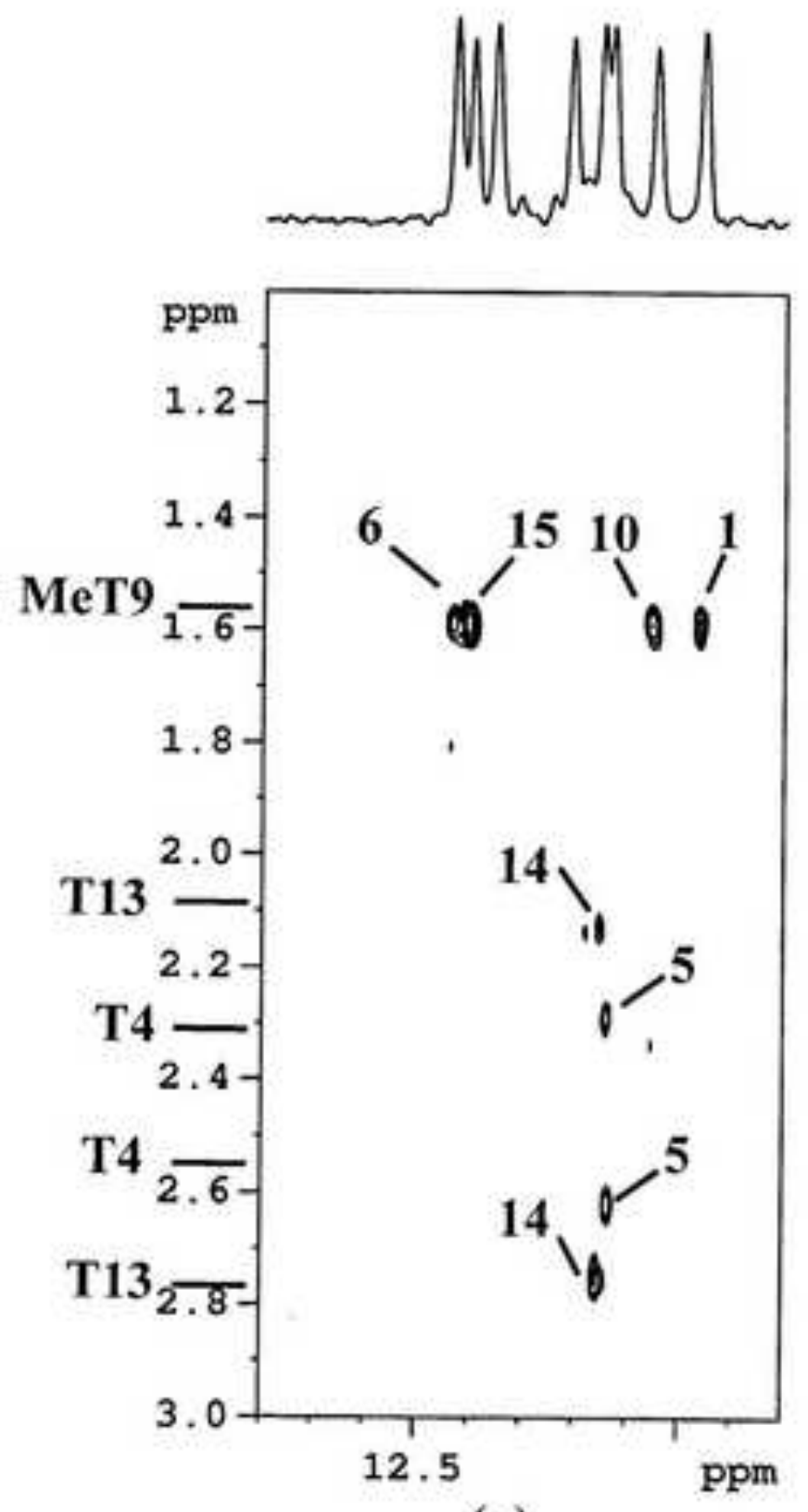

(a)
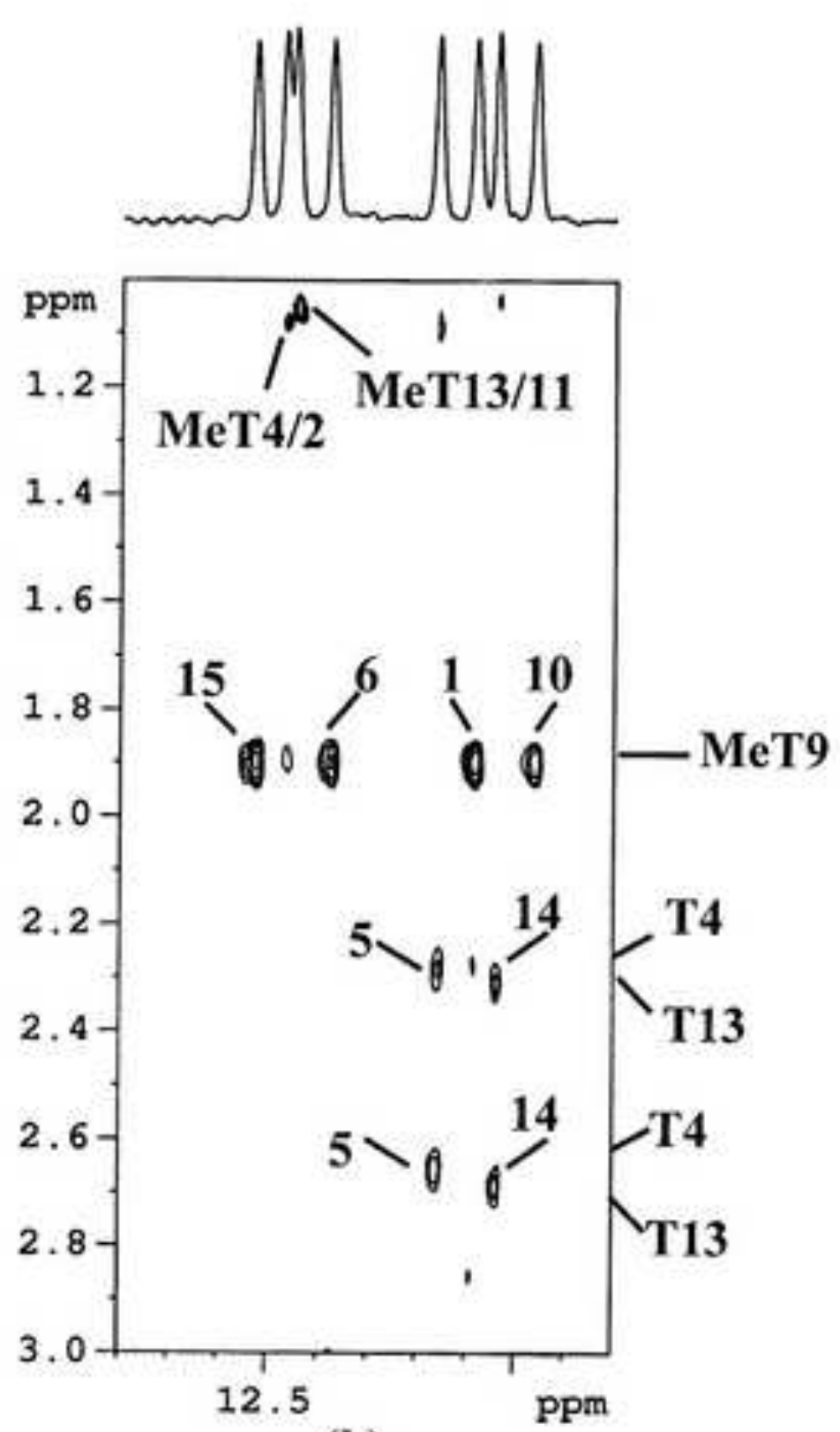

(b) 
Figure 4

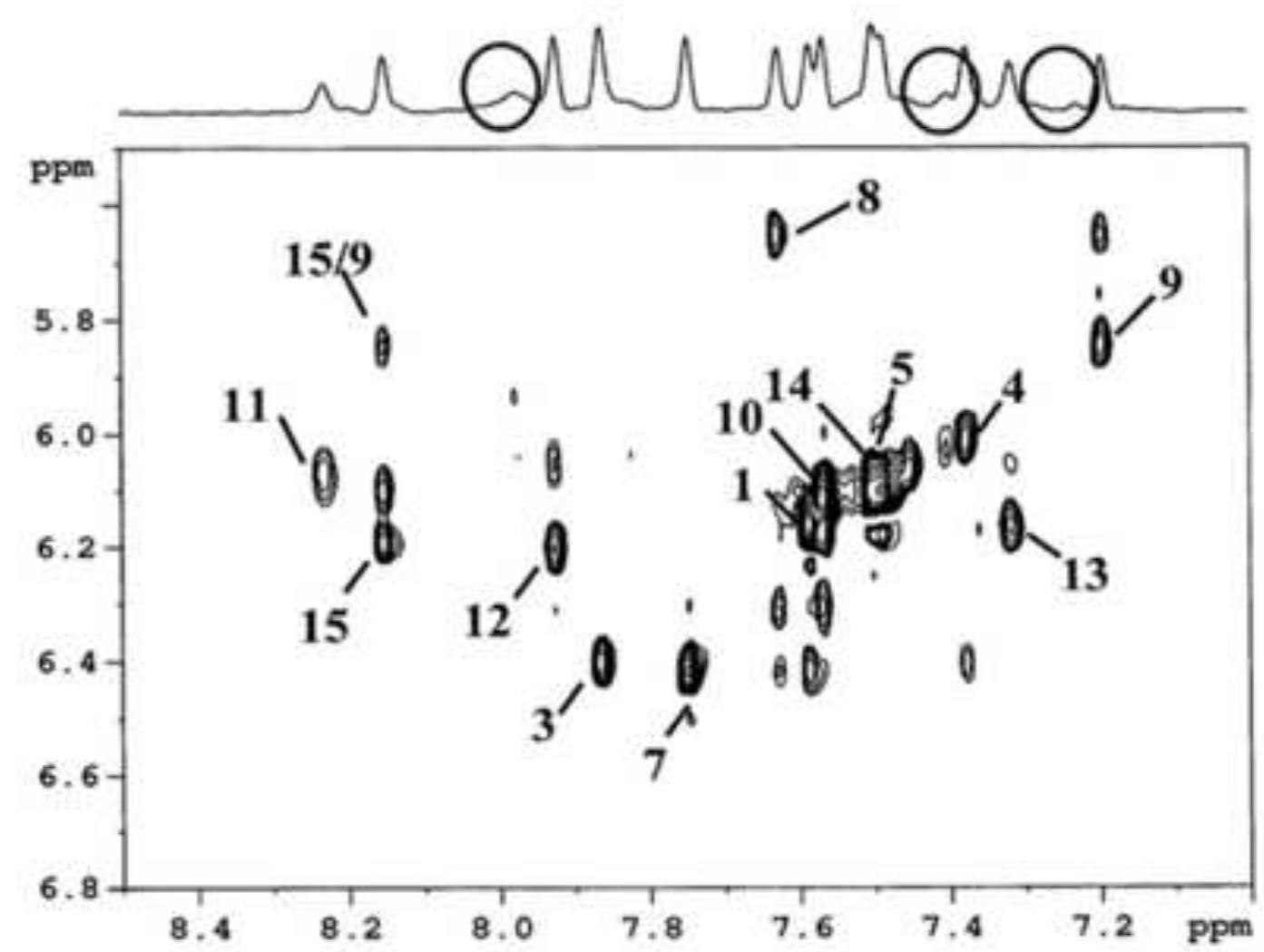

(a)

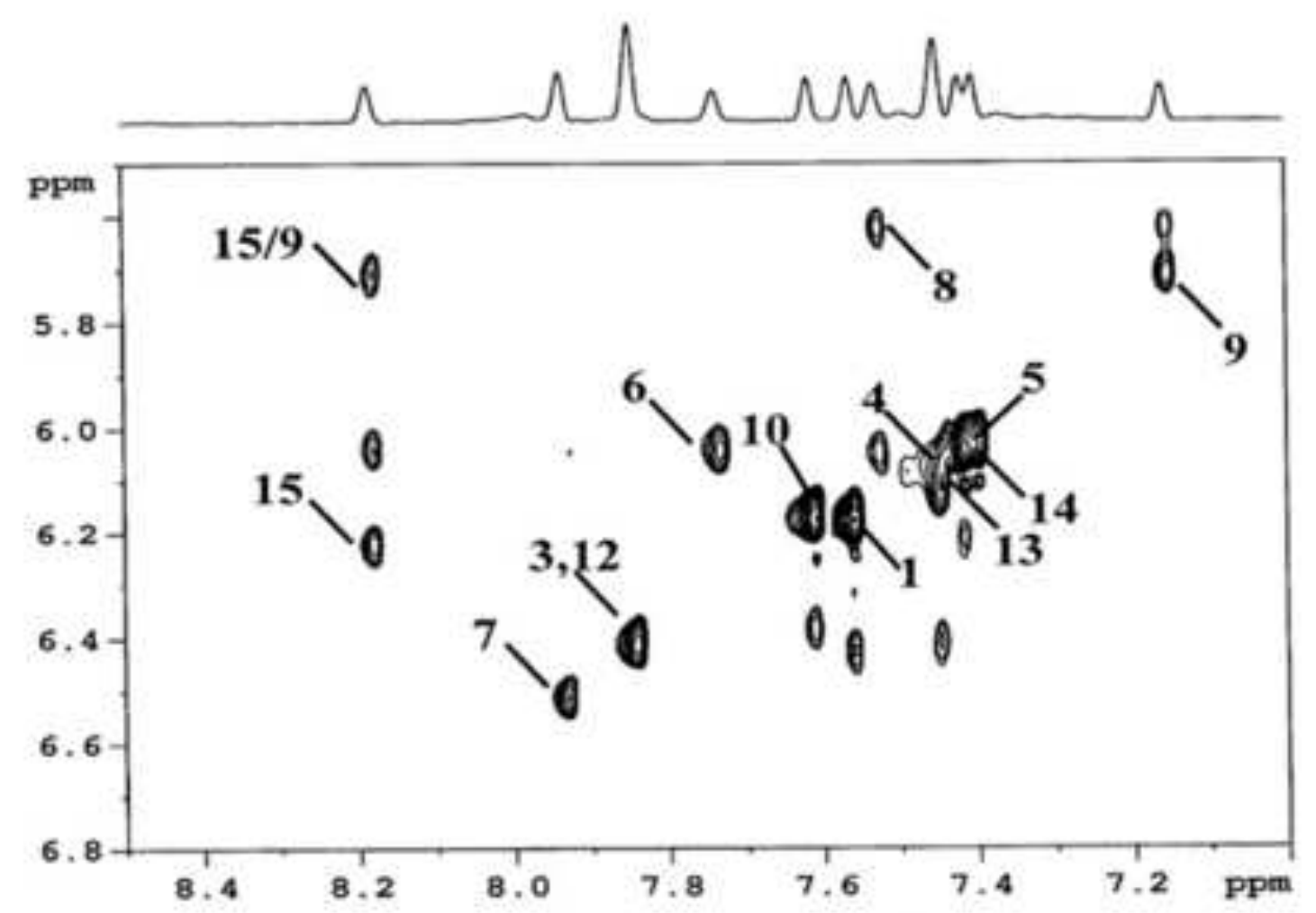

(b) 
$\multimap \mathrm{TBA} 2,6 \mathrm{BrG} \rightarrow \mathrm{TBSA} 2,11 \mathrm{BrG}-\mathrm{TBA} \longrightarrow \mathrm{TBA} 2 \mathrm{BrG} \rightarrow \mathrm{TBA} 5 \mathrm{BrG}$

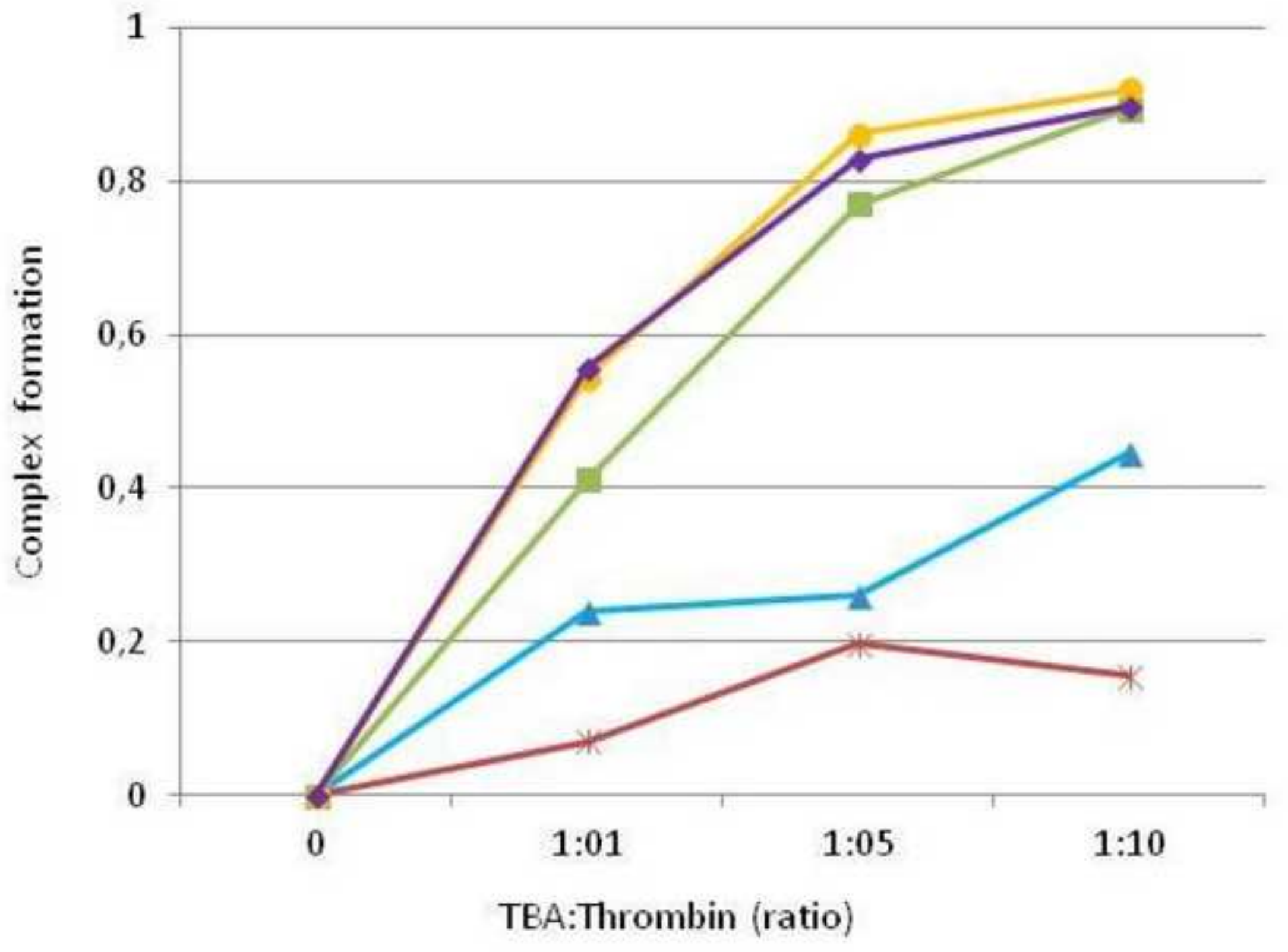

